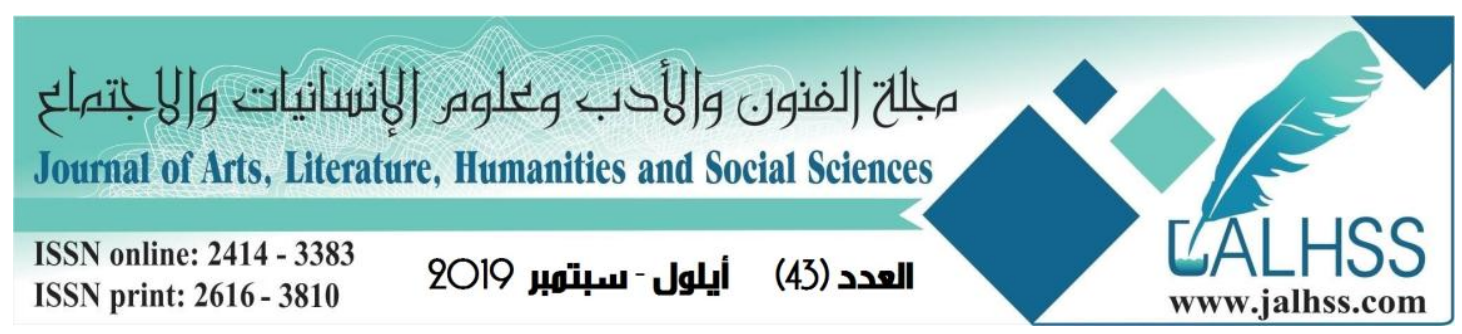

\title{
العلاقات الأمريكية الكينية 1963- 1978م
}

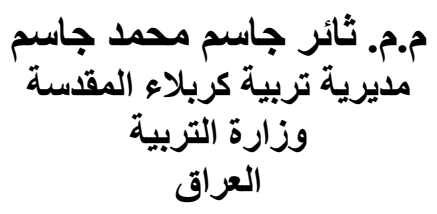

\begin{abstract}
الملخص المان

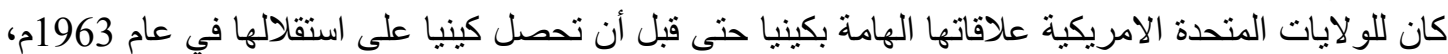

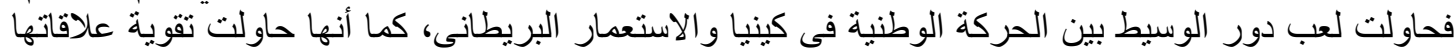

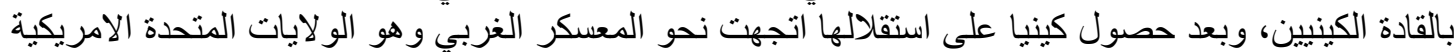

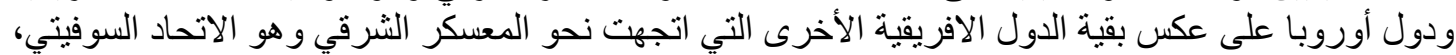

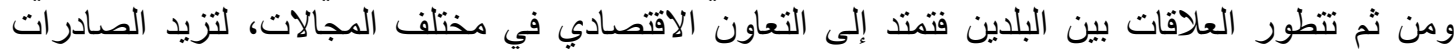

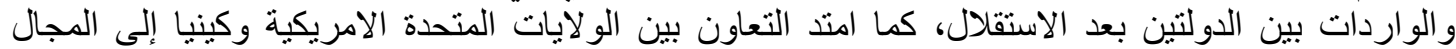

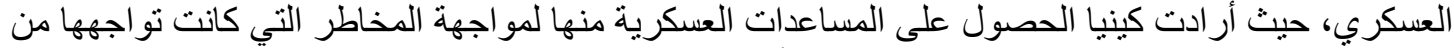
دول الجوار، و التي كان يدعمها الاتحاد السوفيتي العي بالأسلحة المتطورة.
\end{abstract}

\section{US-Kenya Relations 1963-1978}

\begin{abstract}
The United States had important relations with Kenya even before Kenya gained its independence in 1963, It tried to act as a mediator between the national movement in Kenya and British colonialism, Unlike other African countries that have moved towards the eastern camp, the Soviet Union, the relations between the two countries develop into economic cooperation in various fields, increasing exports and imports between the two countries after independence, Cooperation between the United States and Kenya also extended to the military sphere, with Kenya seeking military assistance from it to counter the dangers it faced from neighboring countries, which the Soviet Union supported with sophisticated weapons.
\end{abstract}


مبلحت (لفنون والأدب وكلوه الإنسانيات والبانتمالع

Journal of Arts, Literature, Humanities and Social Sciences

ISSN online: 2414 - 3383

ISSN print: 2616 - 3810

\section{العدد (43) ايلول - سبتمبر 2019}

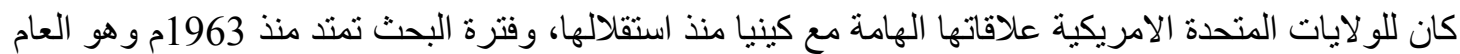

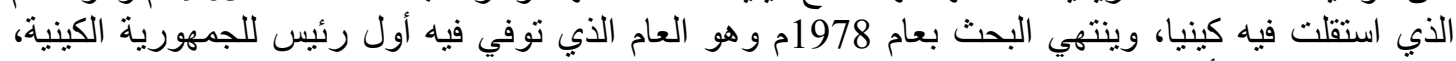
وينقسم البحث إلى أربعة مباحثت رئيسية:

المبحث الأول: العلاقات الامريكية الكينية قبل عبل عام 1963م.

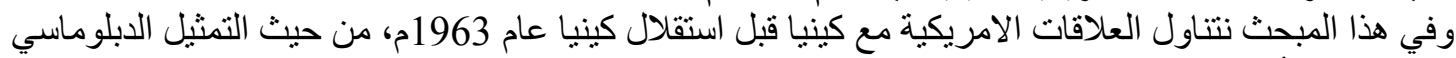

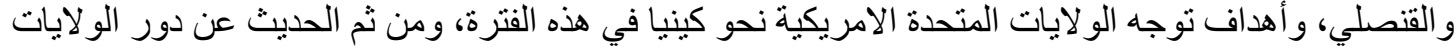

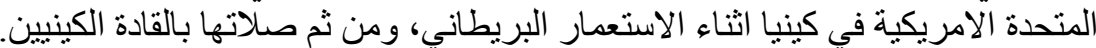

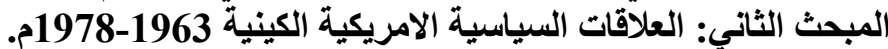

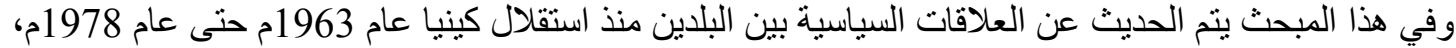

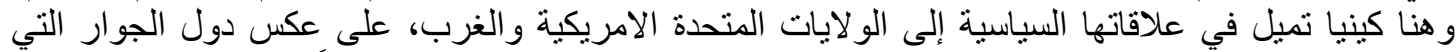

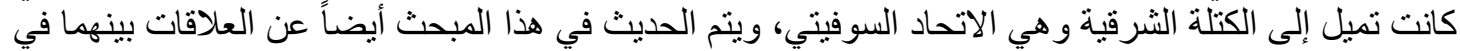

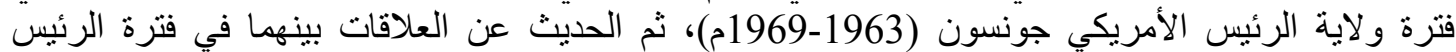

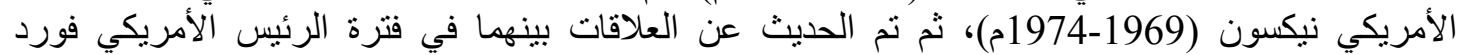

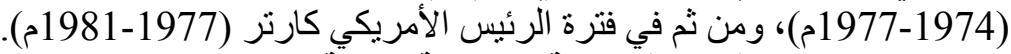

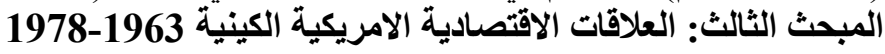

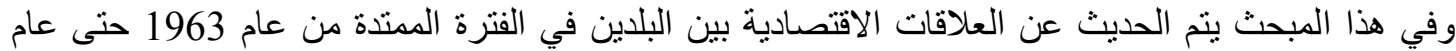

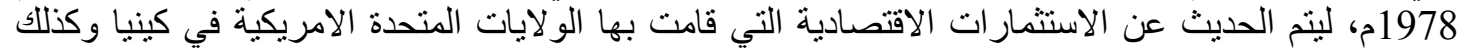

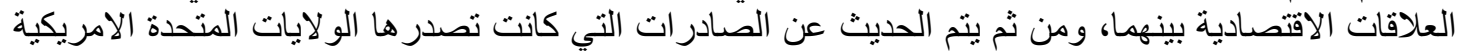

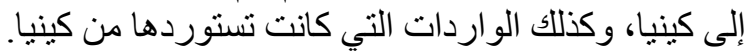

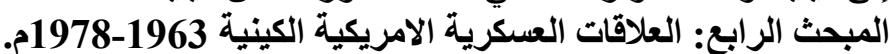

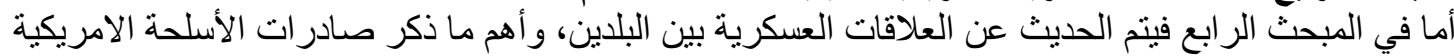

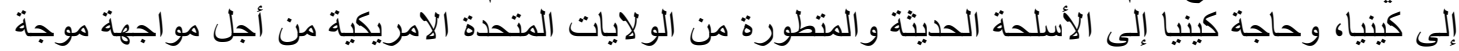

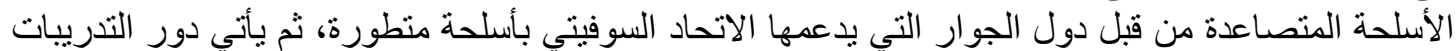

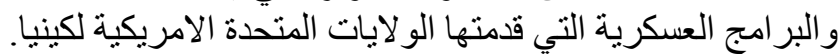

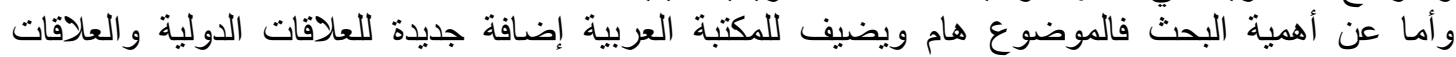

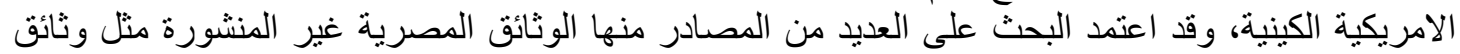

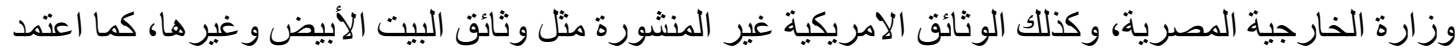

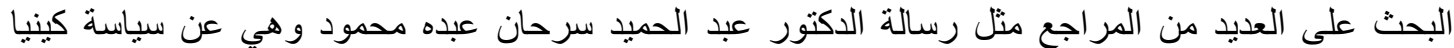
الخارجية 1963-1978م، وكذلك الاعتماد على بعض الصحف و الدوريات العربية والأجنبية.

\section{المبحث الأول العلاقات الامريكية الكينية قبل عام 1963م الإيكا}

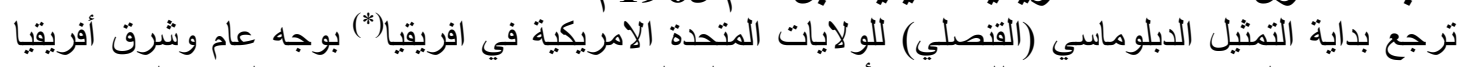

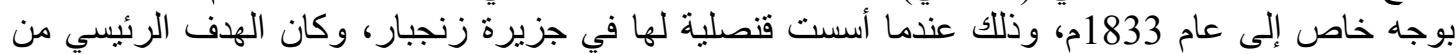

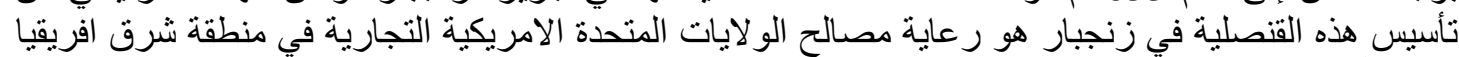

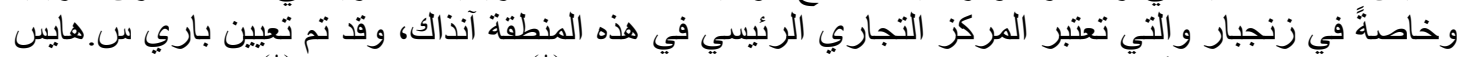

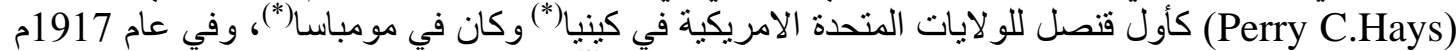

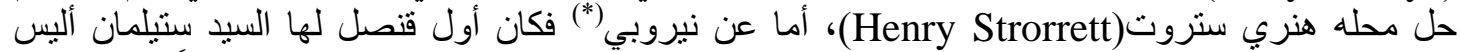

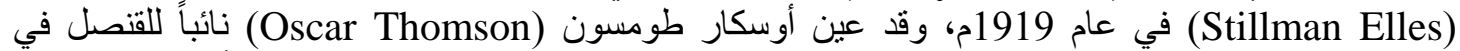

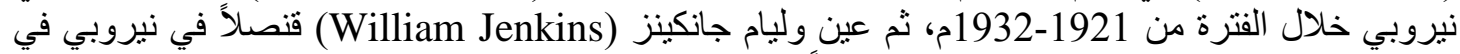

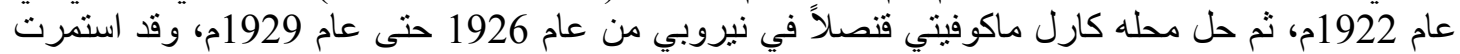




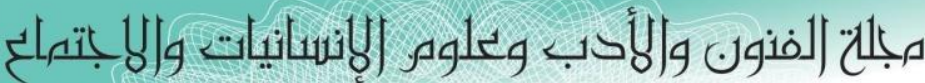

Journal of Arts, Literature, Humanities and Social Sciences

ISSN online: 2414 - 3383

ISSN print: 2616 - 3810

\section{أيلول - سبتمبر 2019}

العدد (43)

الو لايات المتحدة الامريكية في تعيين قناصل لها في مومباسا ونيروبي حتى عام 1943م عندما عينت كونيكي

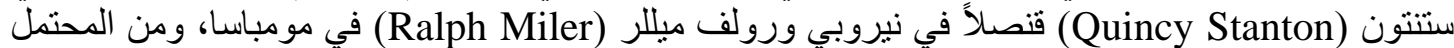

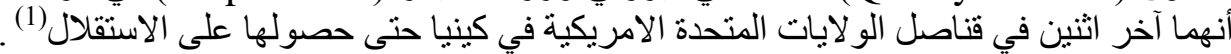

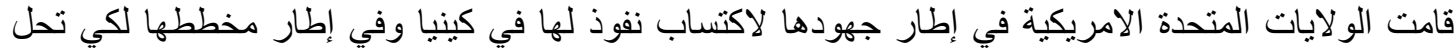

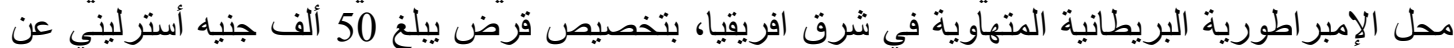

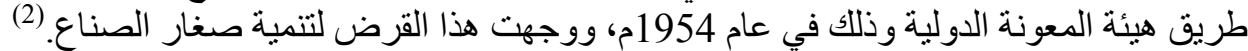

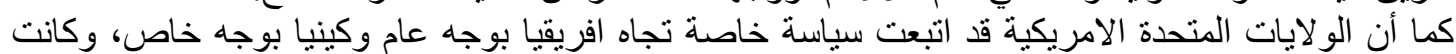
ذات بواعث محددة تلتمثل في الآتي:

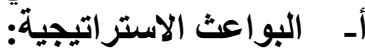
وقد أرجع الخبر اء الأمريكيين أهمية القارة الافريقية من الناحية الاستر اتيجية إلى:

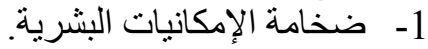

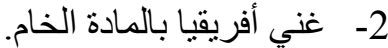

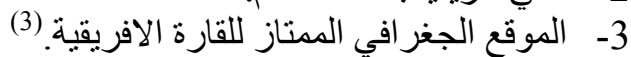

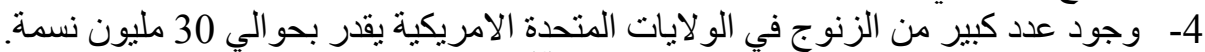

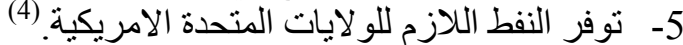

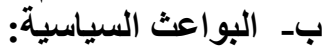
و وهنا يمكن اجمال البو اعث السياسية في:

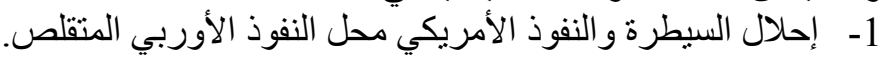
-2 - - - منع تسرب الثيو عية إلى القارة الافريقية.

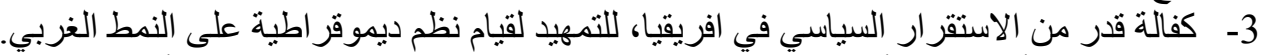

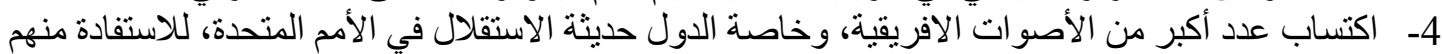

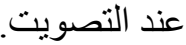

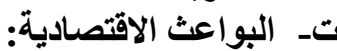
1- تحتاج الولايات المتحدة الامريكية لاستيراد خمس احتياجاتها من المواد الأولية اللازمة لمواجهة طلبات

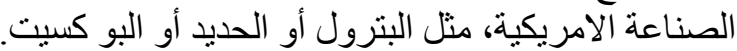

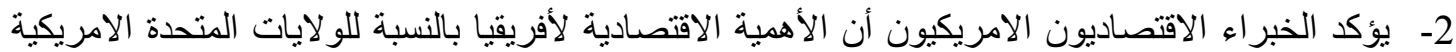

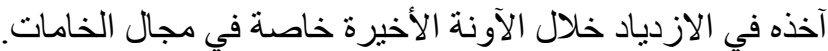

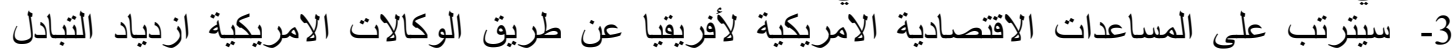
التجاري بين الو لايات المتحدة الامريكية و افريقيا.

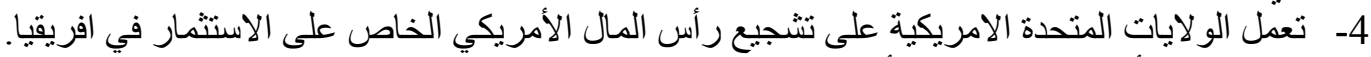

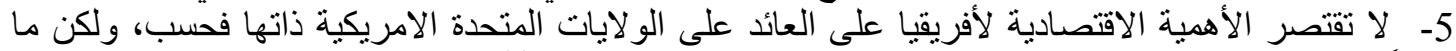

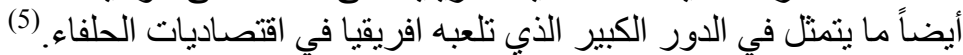

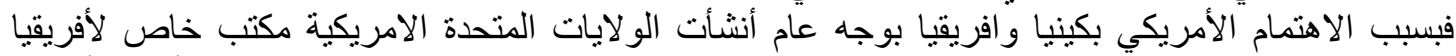

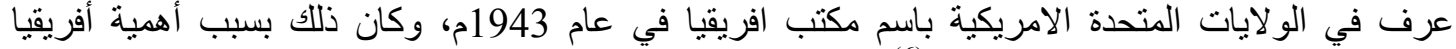

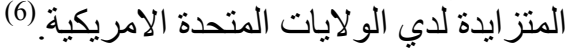

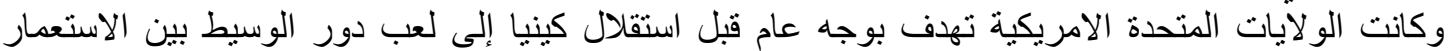
البريطاني ورجال القوي الوطنية في كينيا، فكانت الو لايات المتحدة الإنيات الامريكية تؤيد الاستعمار البريطاني في كينيا

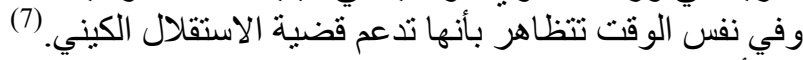

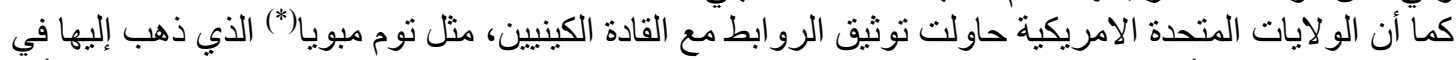

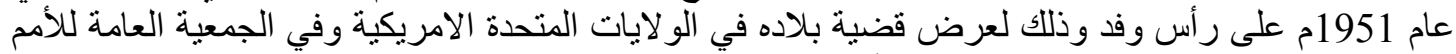

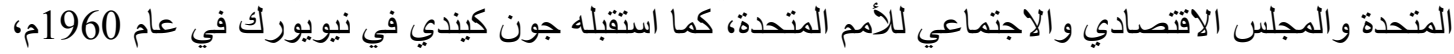


مبلحت (لفنون والأدب وعلوه الإنسانيات والبانتمالع Journal of Arts, Literature, Humanities and Social Sciences

ISSN online: 2414 - 3383

ISSN print: 2616 - 3810

أيلول - سبتمبر 2019

العدد (43)
LALHSS

WWw.jalhss.com

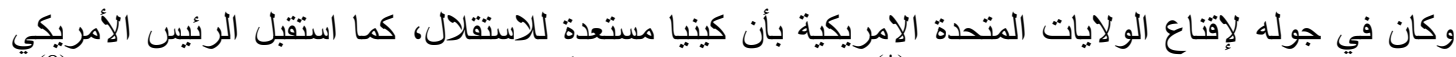

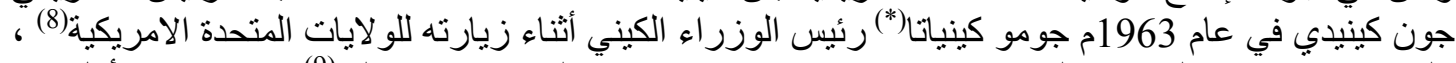

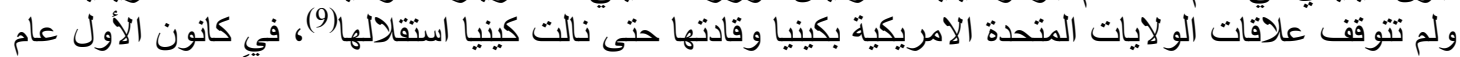

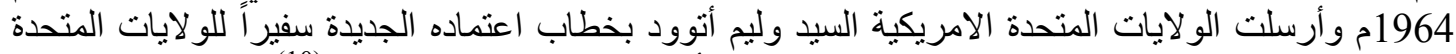

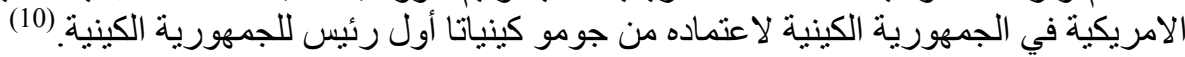

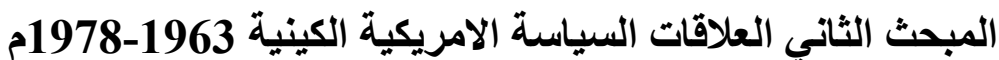

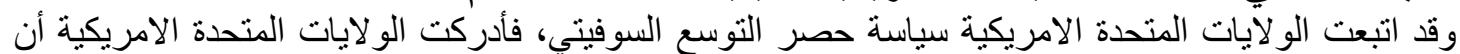

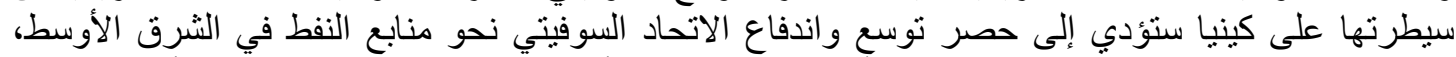

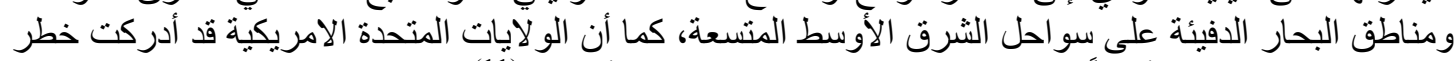

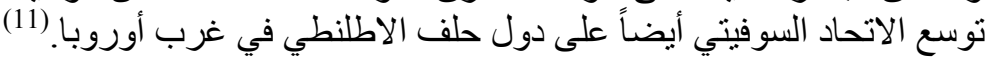

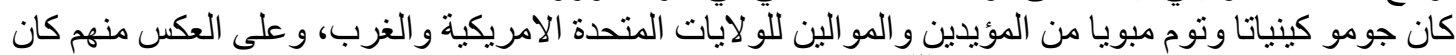

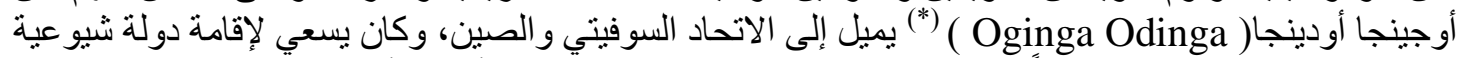

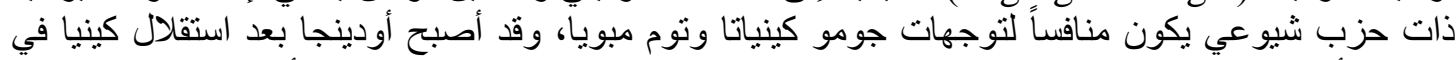

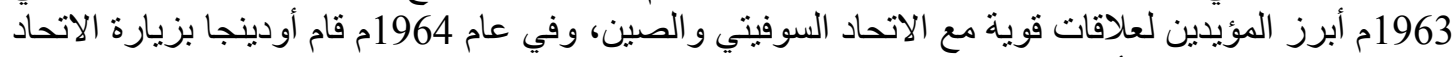

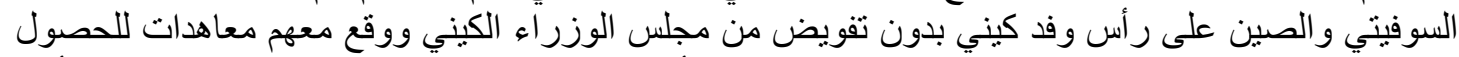

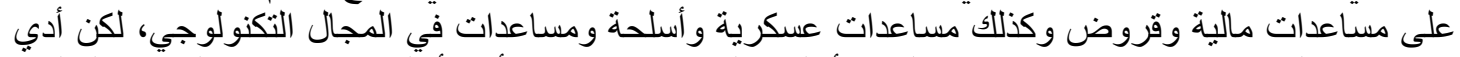
هذا الامر إلى نتائج عكسية، فعندما وصلت الأسلحة إلى كينيا اكتشفت أنها أسلحة قديمة منذ الحرب العالية العالمية الكية الاولي. (12) الإنى

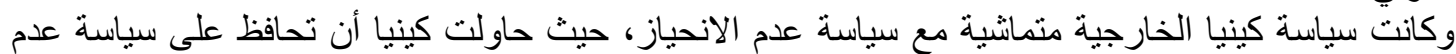

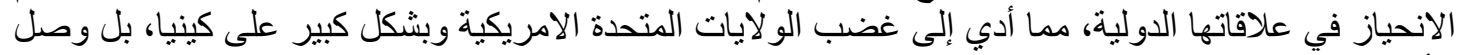

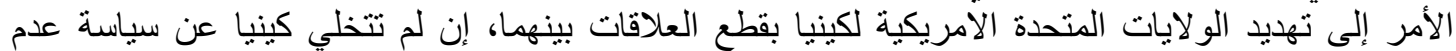

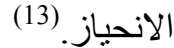

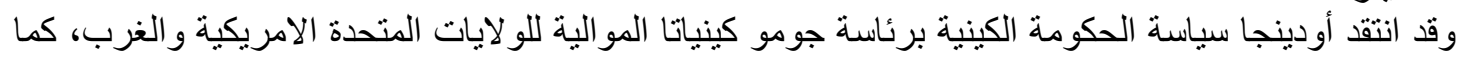

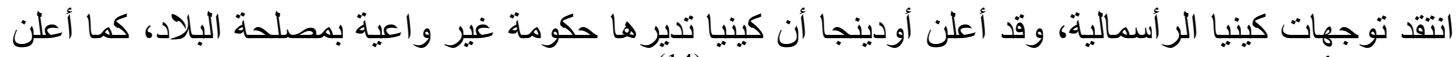

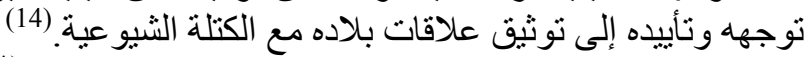

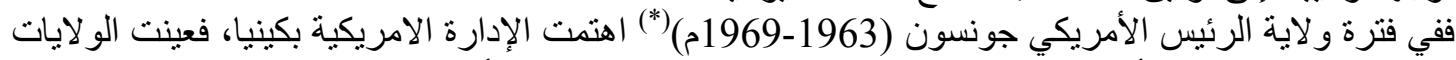

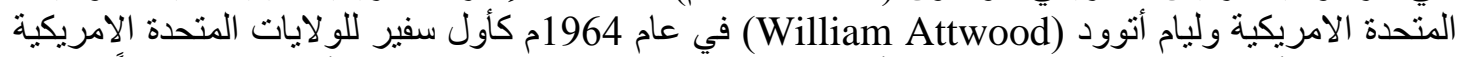

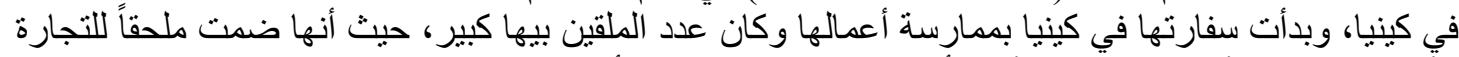

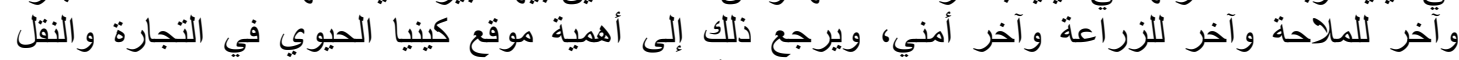

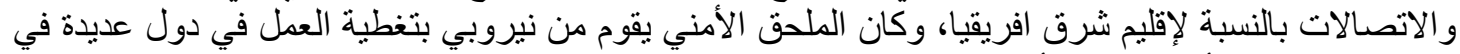

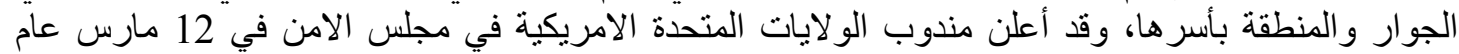

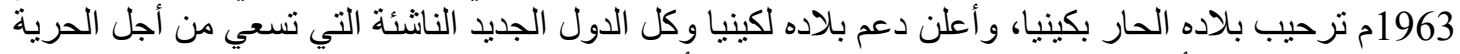

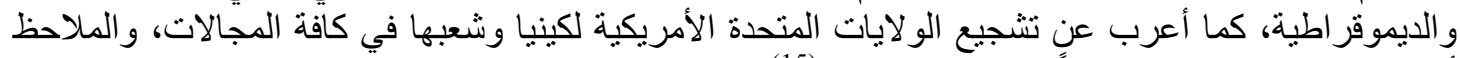

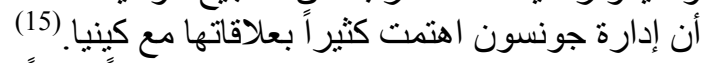

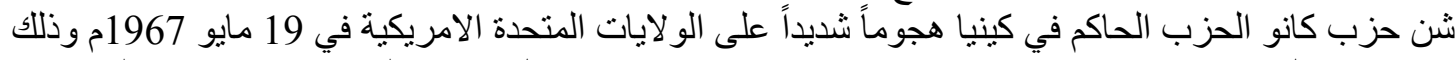

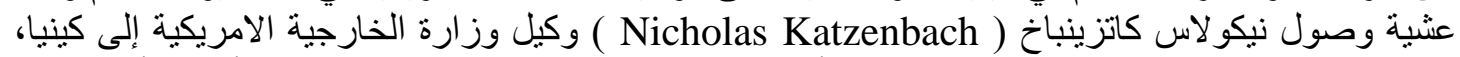

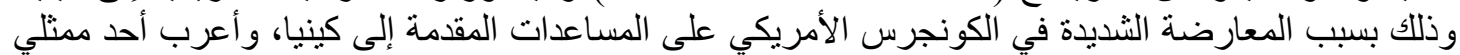

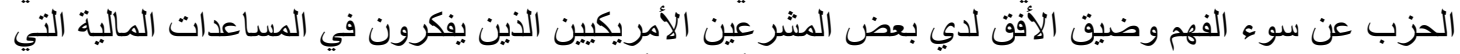

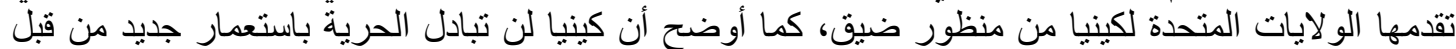

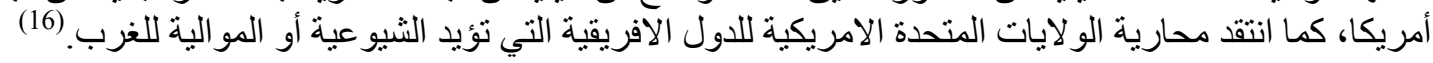




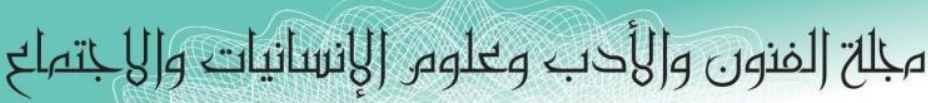
Journal of Arts, Literature, Humanities and Social Sciences

ISSN online: 2414 - 3383

ISSN print: 2616 - 3810

\section{أيلول - سبتمبر 2019}

العدد (43)

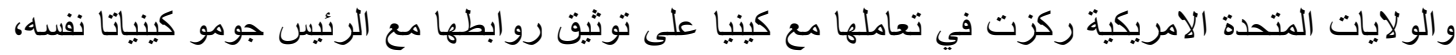

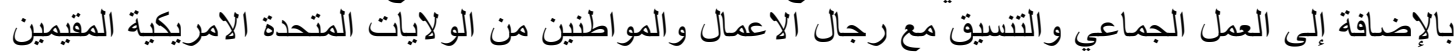

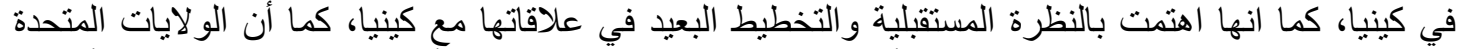

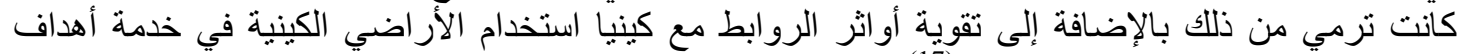
الو لايات المتحدة الامريكية في المنطقة.

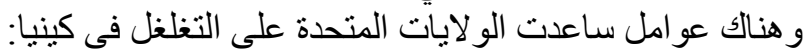

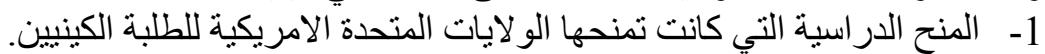

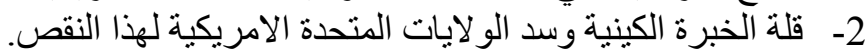

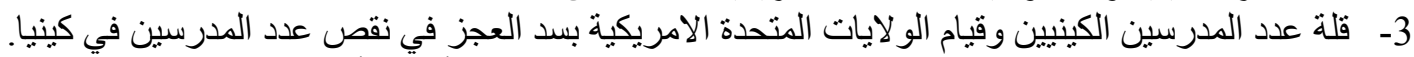

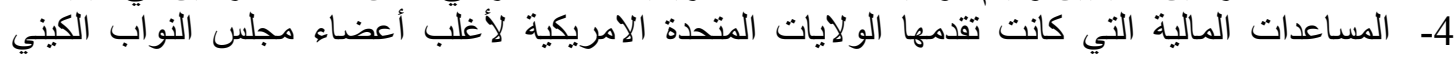

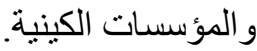

5- استجابة الولايات المتحدة الأمريكية لأي طلب أو معونة من كينيا.

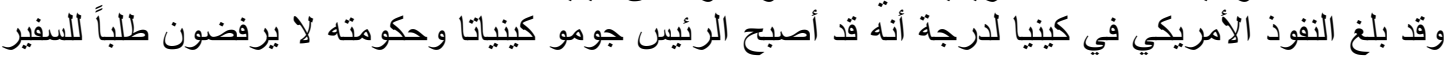

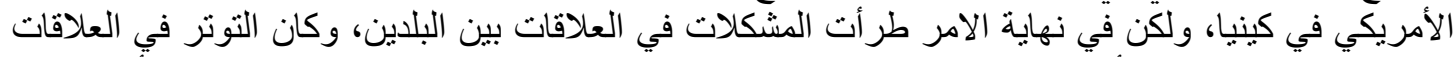

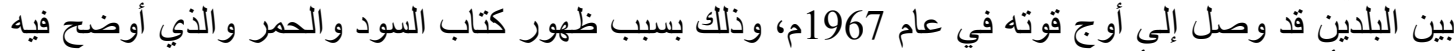

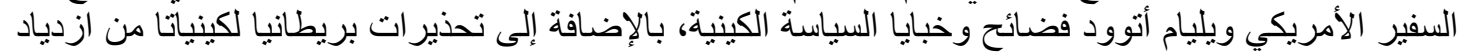

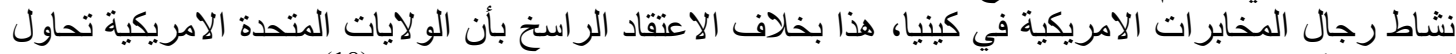

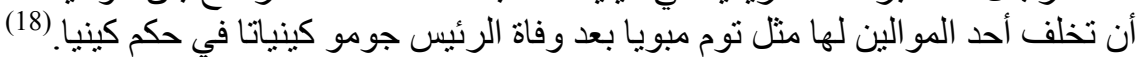

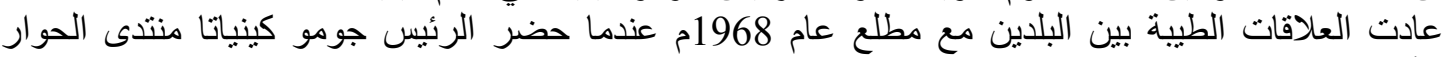

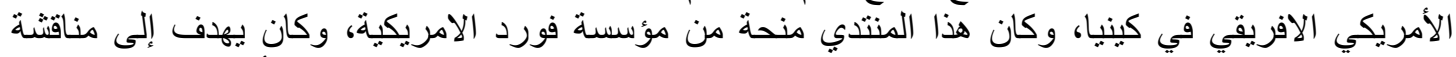

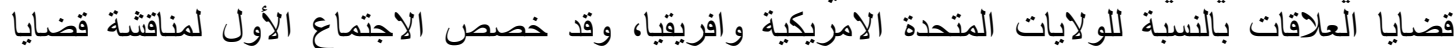

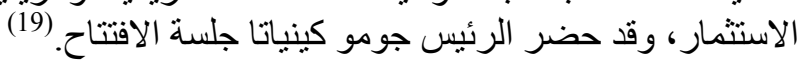

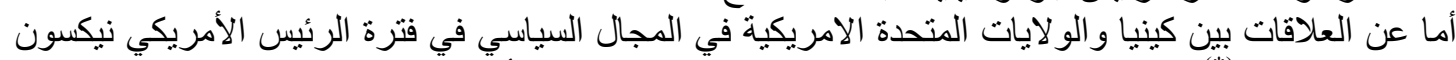

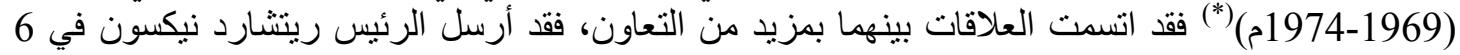

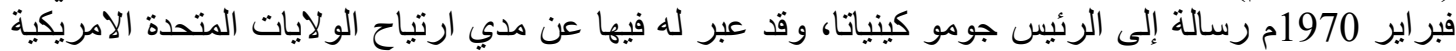

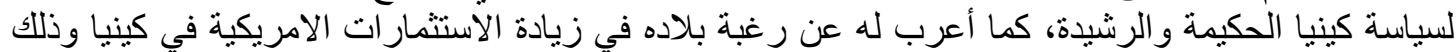

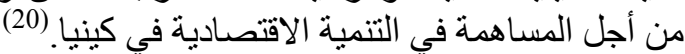

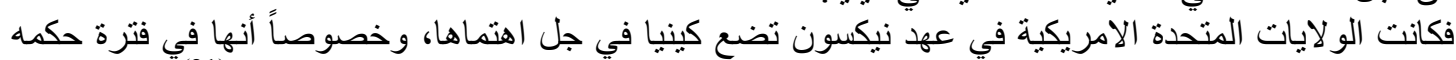

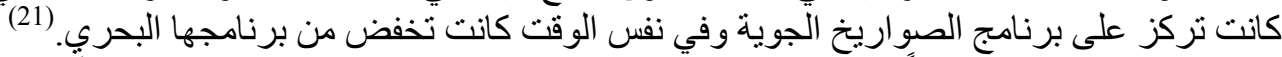

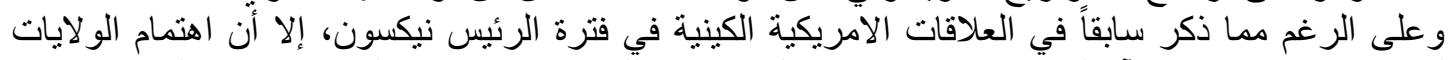

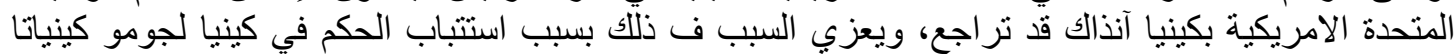

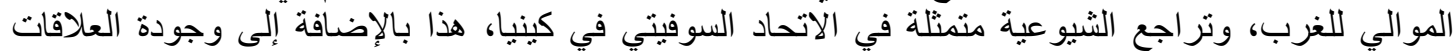

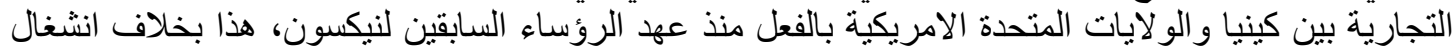

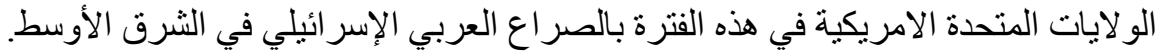

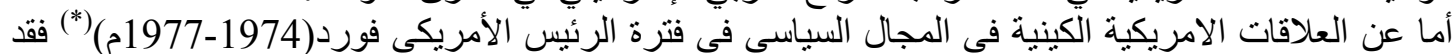

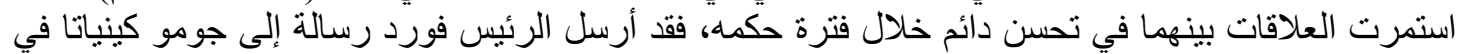

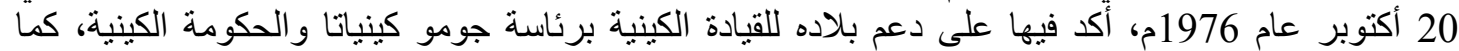

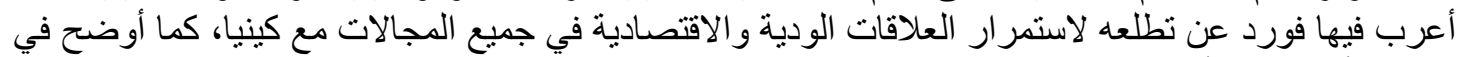

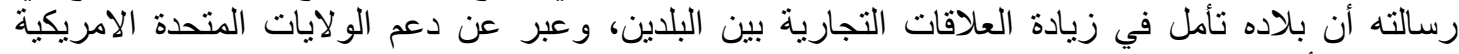

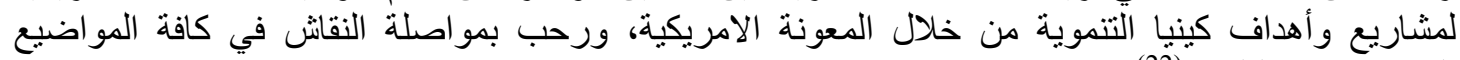

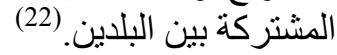




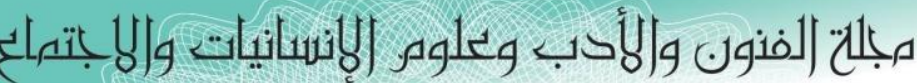

Journal of Arts, Literature, Humanities and Social Sciences

ISSN online: 2414 - 3383

ISSN print: 2616 - 3810

أيلول -سبتمبر 2019

العدد (43)

و وأما عن العلاقات بين البلدين في المجال السياسي في فترة الرئيس الأمريكي كارتر (1977-1981م) (*) فقد

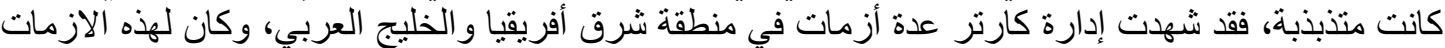

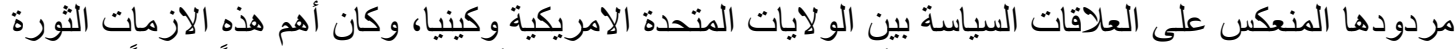

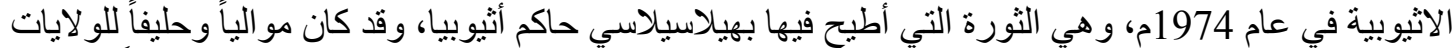

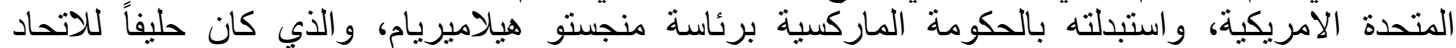

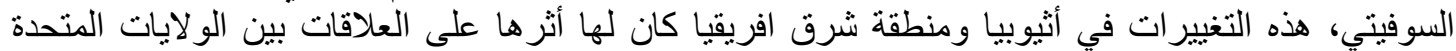

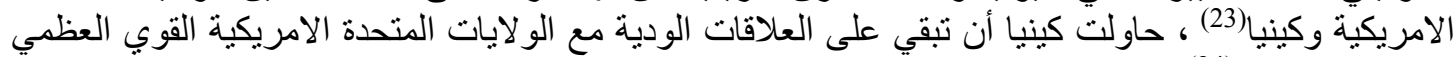

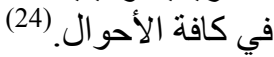

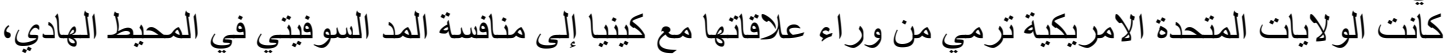

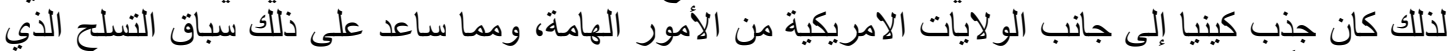

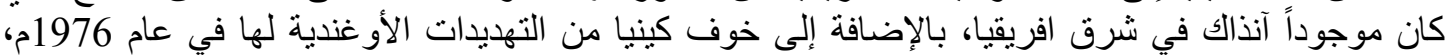

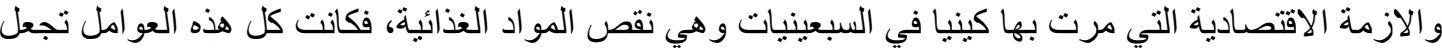

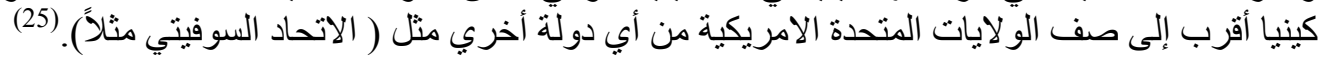

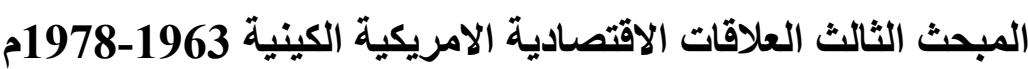

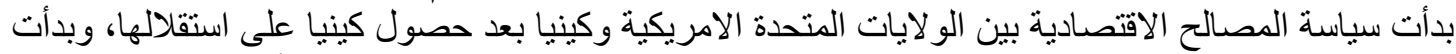

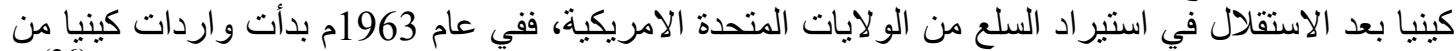

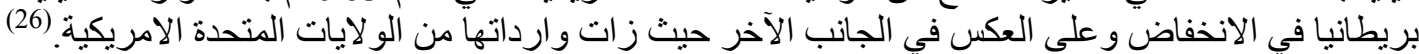

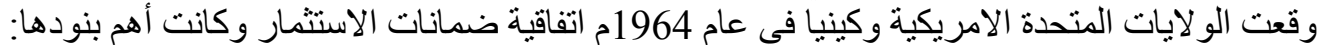

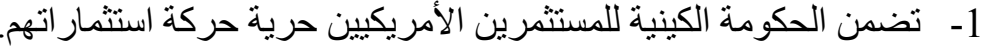

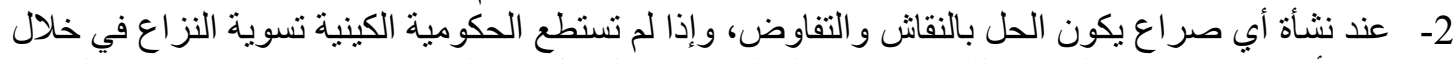

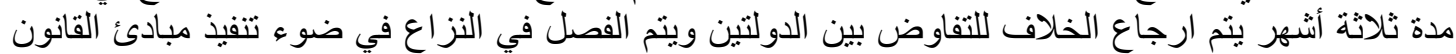

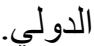

3- توفر كينيا الحماية القانونية للمستثمرين. (27)

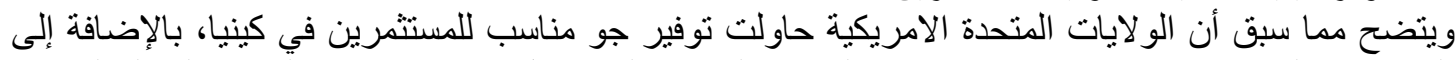

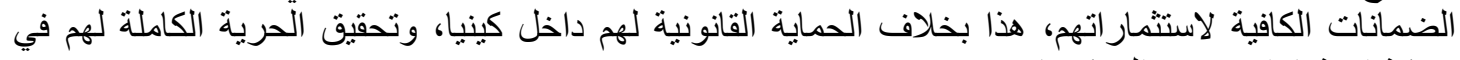
حركة استثمار اتهم من و إلى كينيا.

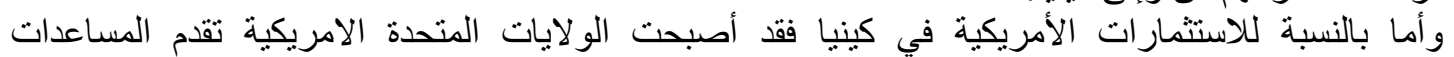

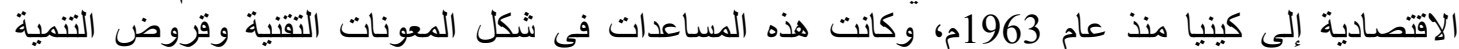

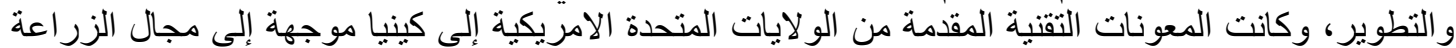

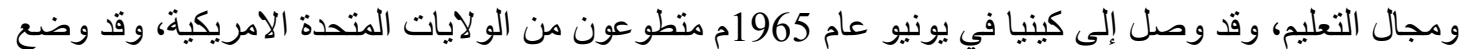

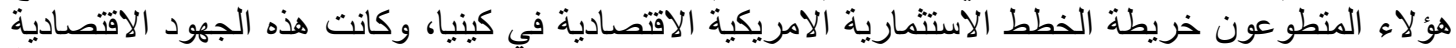

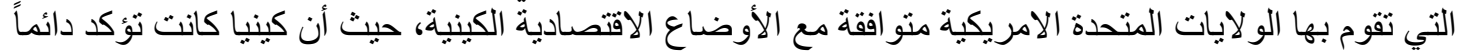

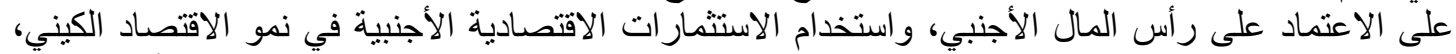

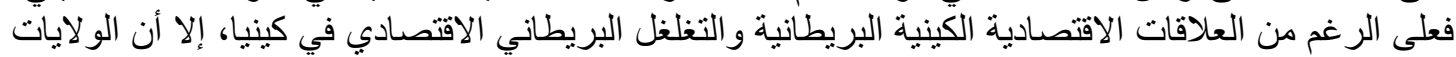

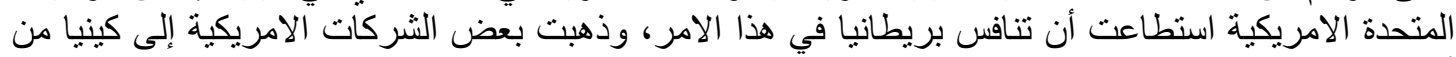

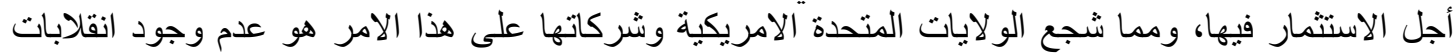

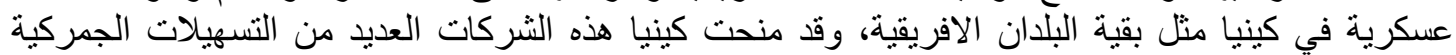
و غير ها في داخل البلاد من أجل الاستمر ار ودعم الاقتصاد الكيني. 


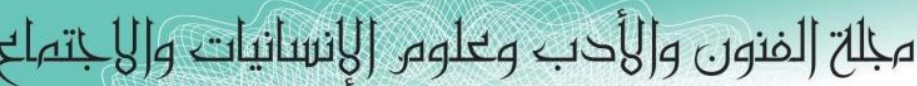

Journal of Arts, Literature, Humanities and Social Sciences

ISSN online: 2414 - 3383

ISSN print: 2616 - 3810

أيلول -سبتمبر 2019

العدد (43)

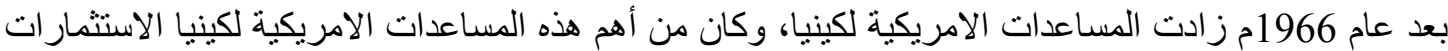

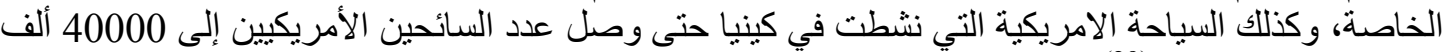

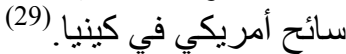

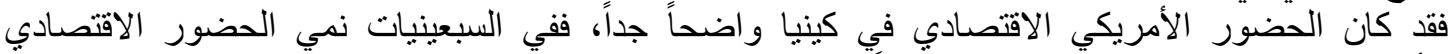

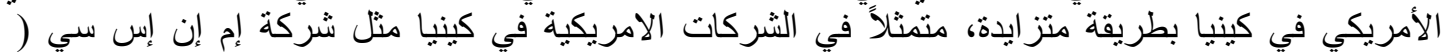

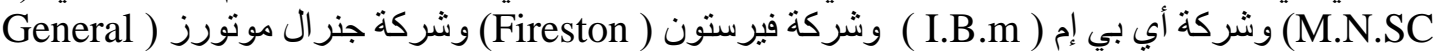

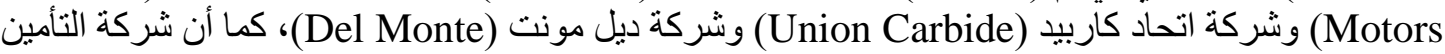

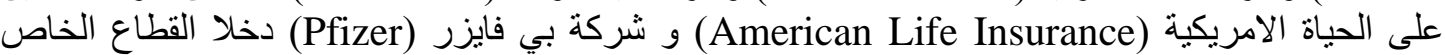

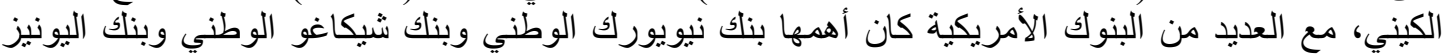

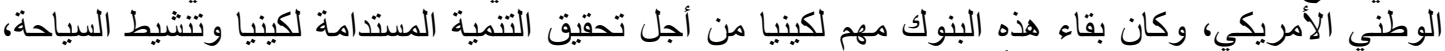

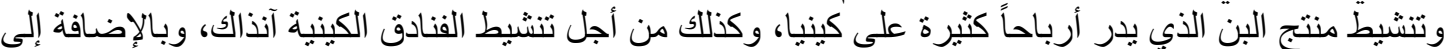

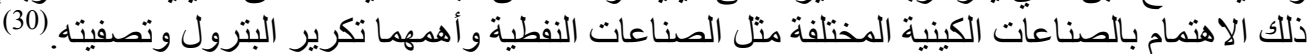

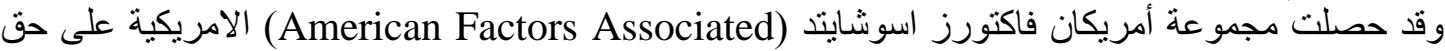

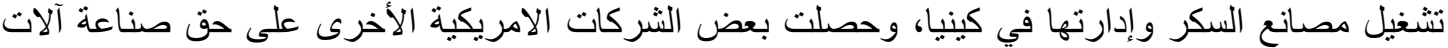

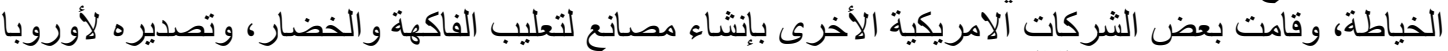

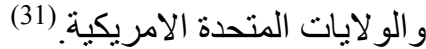
فقد كانت الاستثمار ات الامريكية من الهم محددات التوجه الكيني نحو الولايات الاتيكات المتحدة الامريكية، فكانت كيني

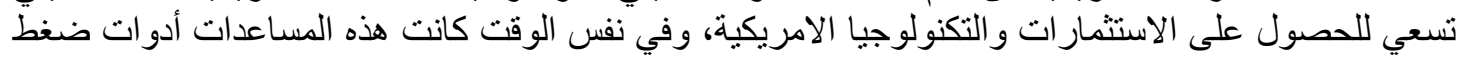

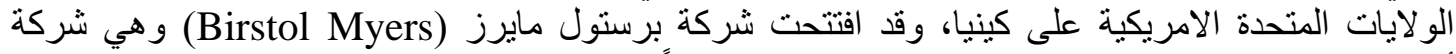

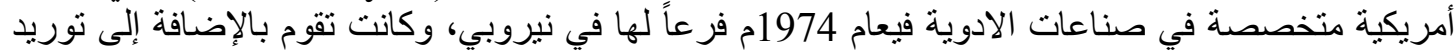

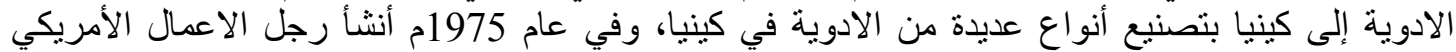

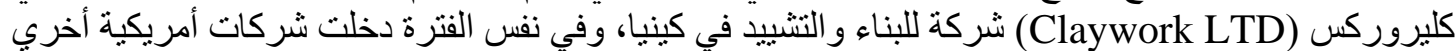

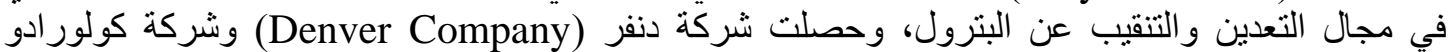
(Colorado)

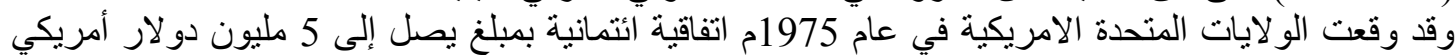

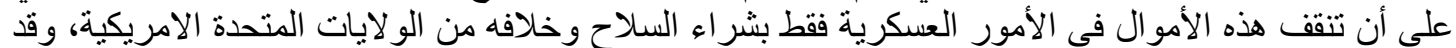

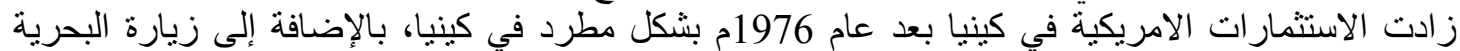

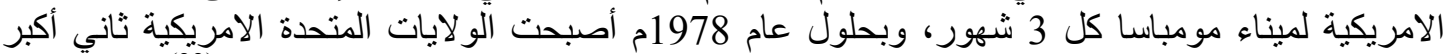

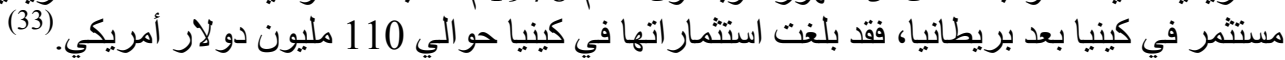

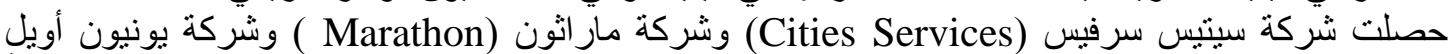

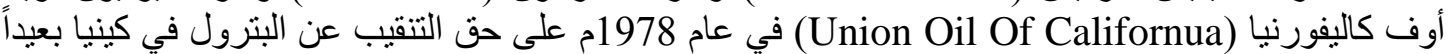

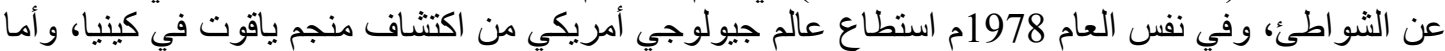

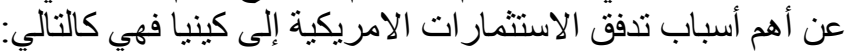

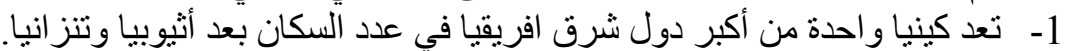

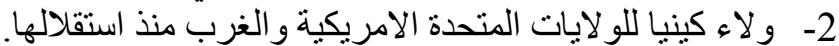

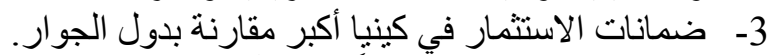

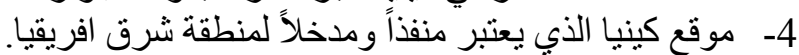

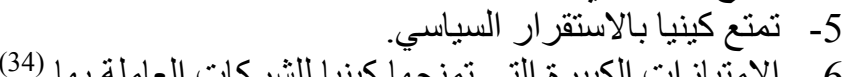


مبلحت (لفنون والأذب وعلوهر الإنسانيات والبانتمالع Journal of Arts, Literature, Humanities and Social Sciences

ISSN online: 2414 - 3383

ISSN print: 2616 - 3810

\section{أيلول - سبتمبر 2019}

العدد (43)

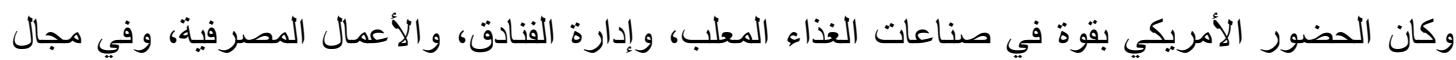

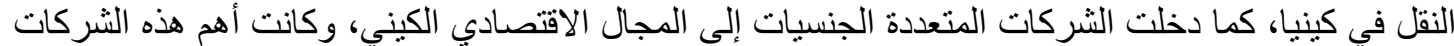

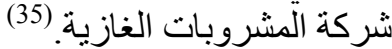

أما عن الصادرات و الواردات بئرات بين الواتلايات المتحدة والأمريكية وكينيا فلم يكن الامر بالجداتيد، فمنذ الاستعمار

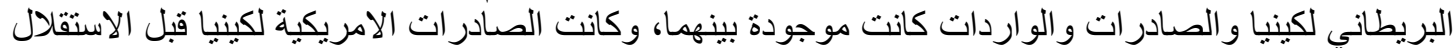

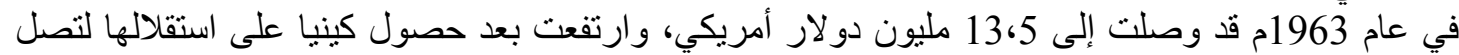

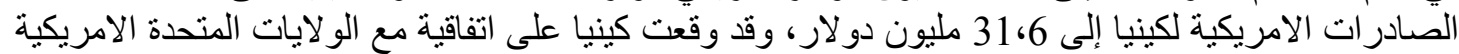

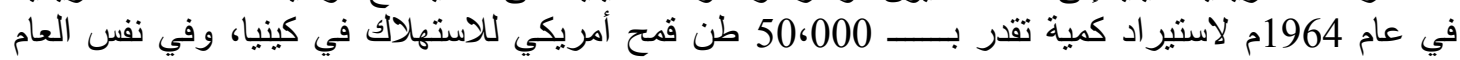

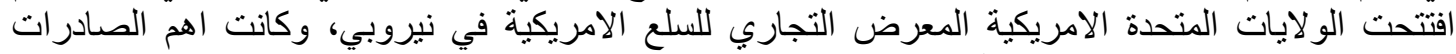

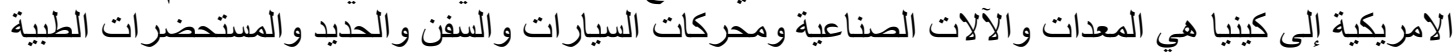

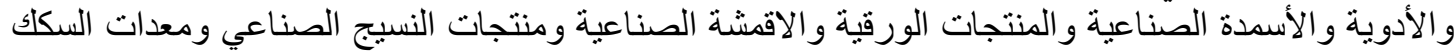

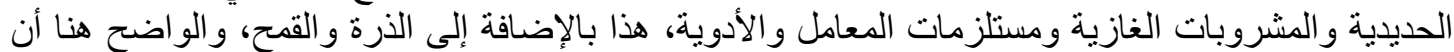

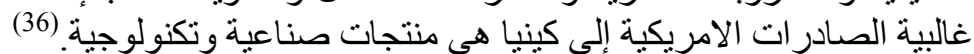

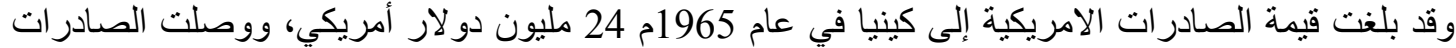

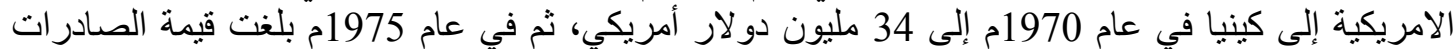
الامريكية إلى كينيا 49 مليون دو لار أمريكي.

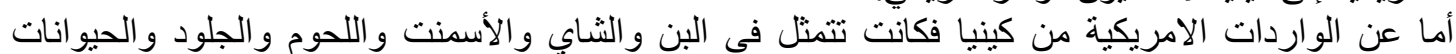

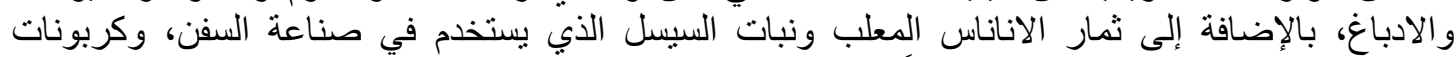

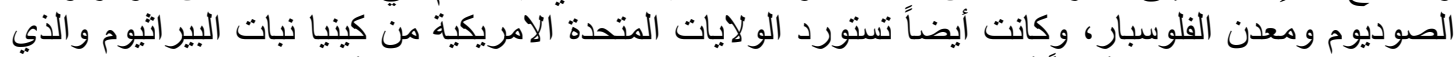

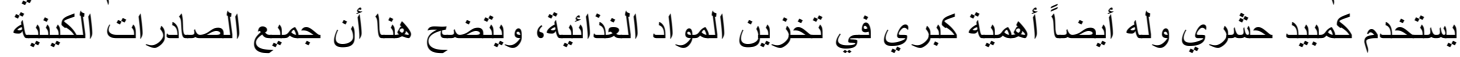

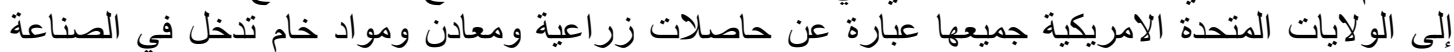

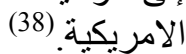

وبلغت قيمة الواردات الامريكية من كينيا في عام 1964م 1965 الامبرة000،760،23 مليون دولار أمريكي، كما بلغت

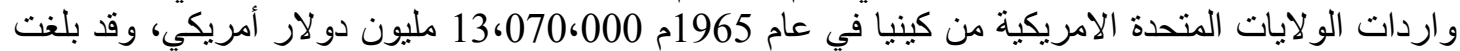
الواردات الامريكية من كينيا في عام 1970م 23 مليون دولار الاريكات أمريكي، وفي عام 1975م بلغت 36 مليون دو لار أمريكي. (39)

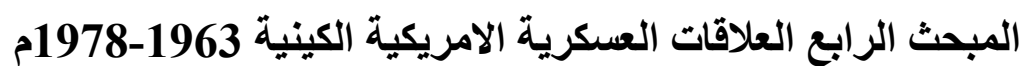

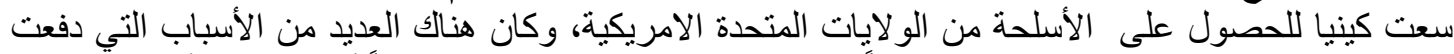

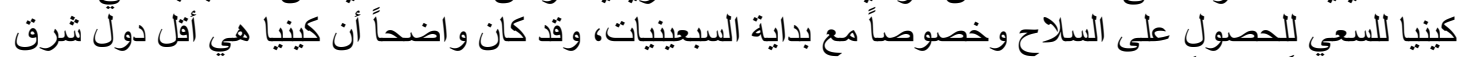

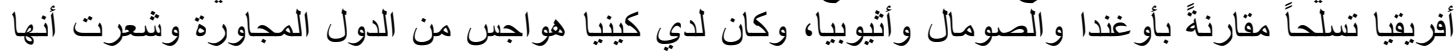

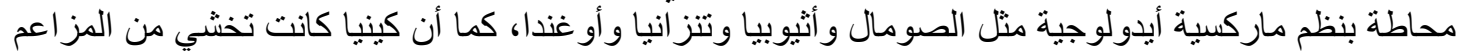

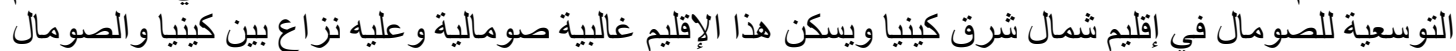

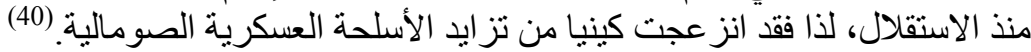

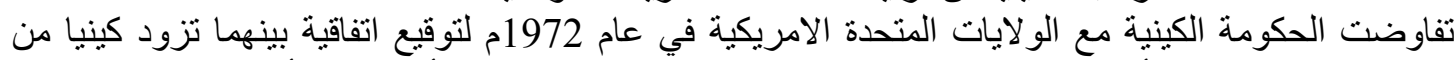

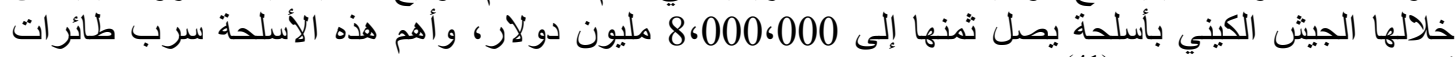

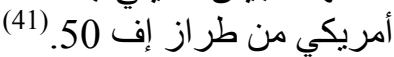

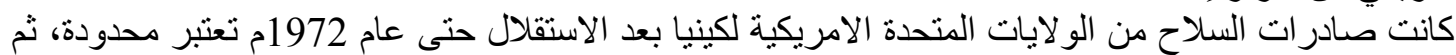

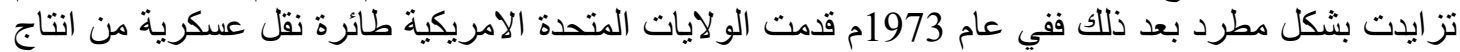

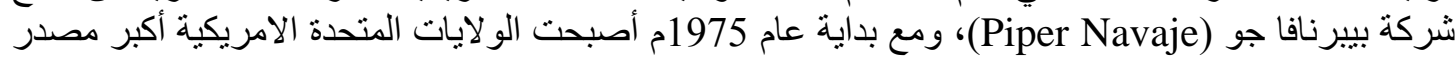

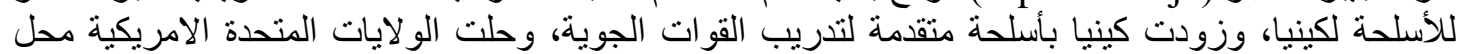


مبلحت (لفنون والأدب وكلوه الإنسانيات والبانتمالع

Journal of Arts, Literature, Humanities and Social Sciences

ISSN online: 2414 - 3383

ISSN print: $\mathbf{2 6 1 6 - 3 8 1 0}$

أيلول - سبتمبر 2019

العدد (43)

بريطانيا كأكبر داعم ومزود لكينيا باحنياجاتها العسكرية ومساعدتها في بناء قواتها الجوية للمساعدة في الدفاع

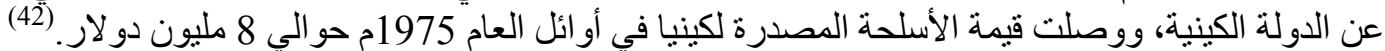

أوصي جيمس تي لين (James T. Lynn) التابع لوزارة الخارجية الامريكية الرئيس الأمريكي فورد في في 24

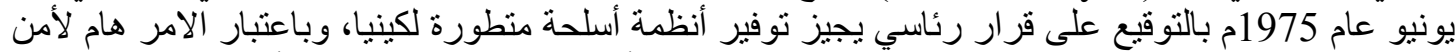

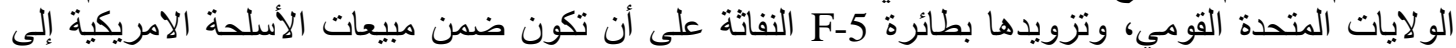

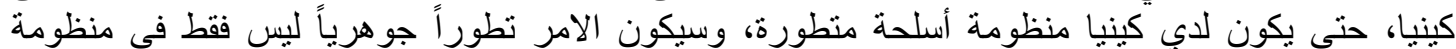

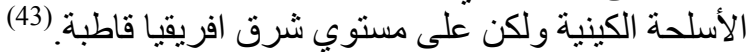

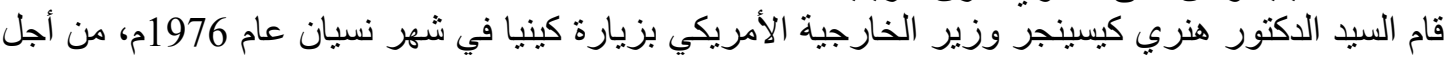

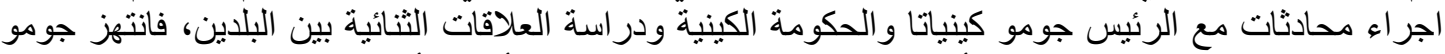

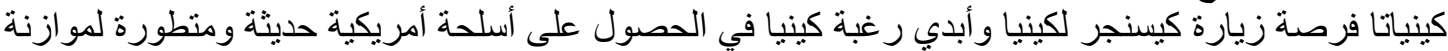

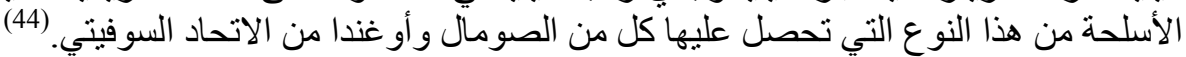

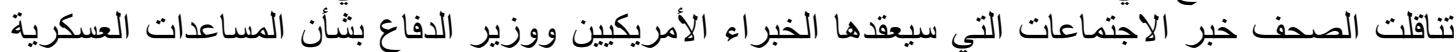

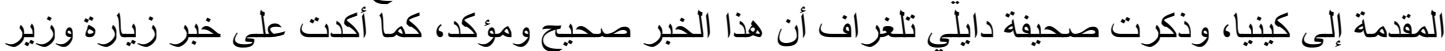
الدفاع الأمريكي دو نالد ر امسفيلد إلى عدة دول أفريقية، وأن هذه الزيارة ستستغرق مدة ثلاثنة أسابيع (45) ، على أبي

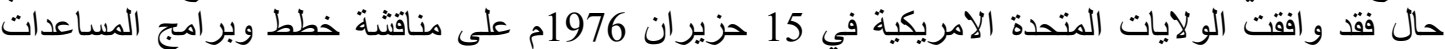
العسكرية لكينيا، وقد عزمت الولايات المتحدة الامريكية على منافسة الأسلحة السوفيتية الفية والنفية النفوذ السوفيتي المتز ايد

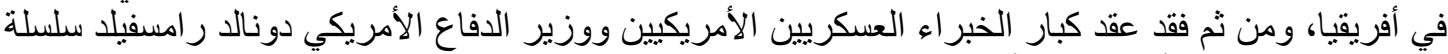

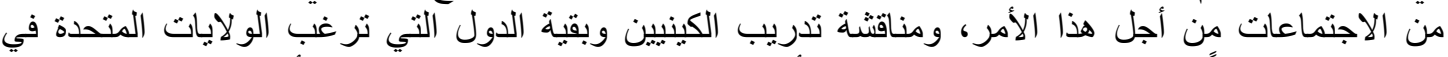

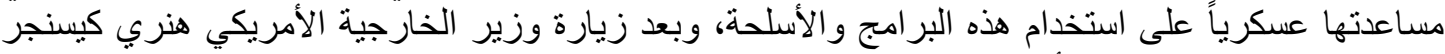

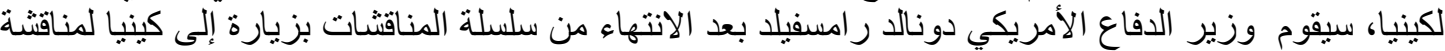
كل الأمور العسكرية بين البلدين، ومنها قيمة المساعدات التي ستقدم إلى كينيا، ففي حالة تخطيها لمبلغ 25 مليون الإن التهاء

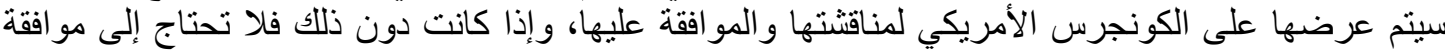
الكونجرس الأمريكي، كذلك سيتم مناقتنة عدد الموظفين الأمريكيين اللازم ارسالهم للإشراف اف على التسليم

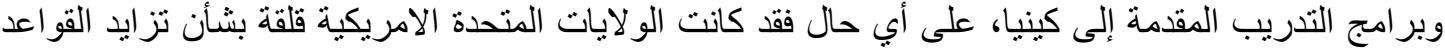

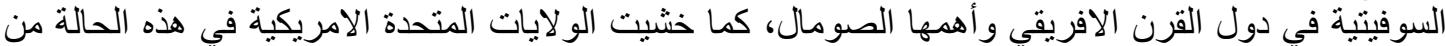
السيطرة السوفيتية على طرق فوف الملاحة البحرية التي يمر فيها النفط المصدر إلى الولائيات المتحدة الامريكية

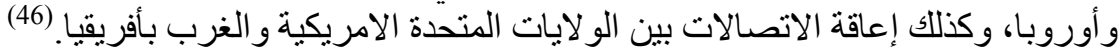

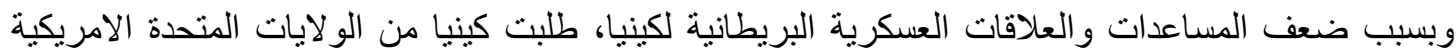

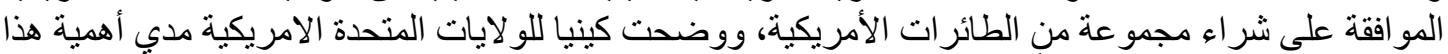

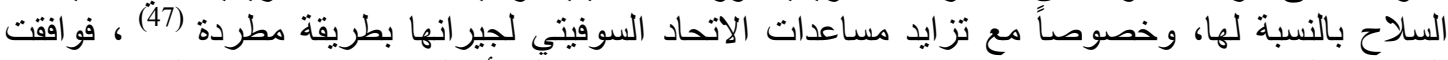
الو لايات المتحدة الامريكية في شهر حزيران عام 1976م من حيث المبدأ على تجهيز كينيا بحو الي 12 طائرة

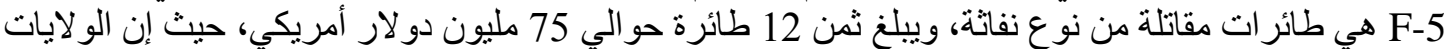

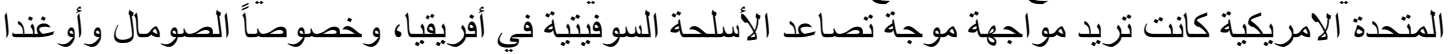
اللتان كانتا متطورتان بشكل كبير في الأسلحة بسبب المساعدات السوفيتية، وهذه الصفية فئة تعتبرة الصنير الأكبر بين

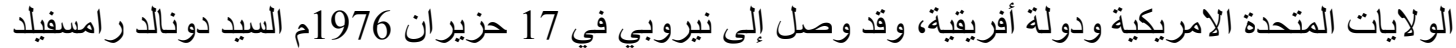

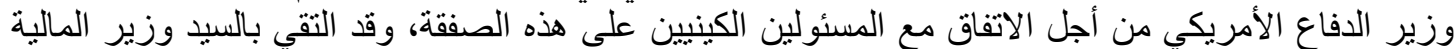

ووزير الدفاع ووزير الأفيري الخارجية بالوكالة الاتفاق (48)

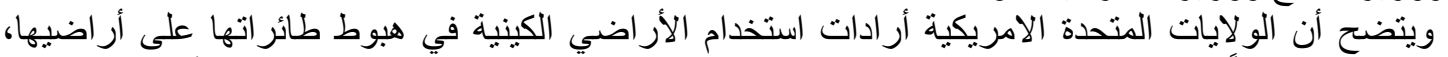

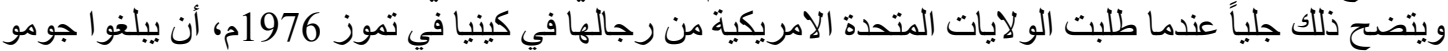
كينياتا بأن الطائرة أي بي -3 ستهبط في نيروبي، هذا بالإضافة إلى دخول الفرقاطّة الامريكية إلى ميناء مو مباسا 


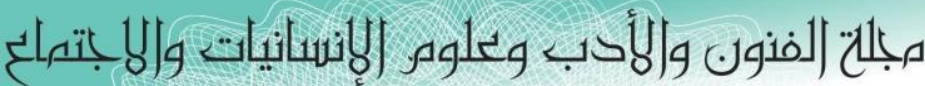

Journal of Arts, Literature, Humanities and Social Sciences

ISSN online: 2414 - 3383

ISSN print: 2616 - 3810

\section{أيلول - سبتمبر 2019}

العدد (43)

في نفس ذات التوقيت، على أن تصل الفرقاطة إلى ميناء مومباسا في 9 تموز وستظل في الميناء لمدة يومين إلى إلى

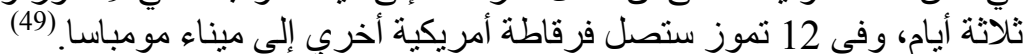

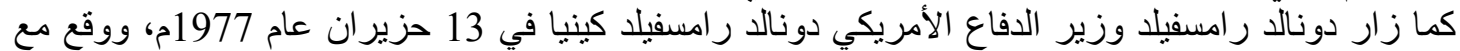
كينيا صفقة أسلحة أمريكية بقيمة 12 مليون دو لار أمريكي إلى كينيا، وتتكون الصفقة من مجموعة طائر ات اتع أمريكية. (50)

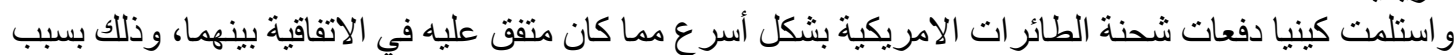

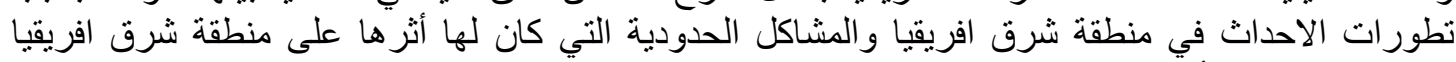

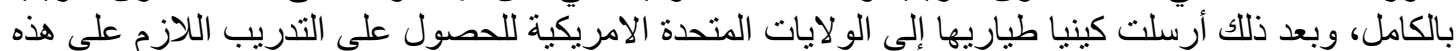

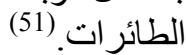

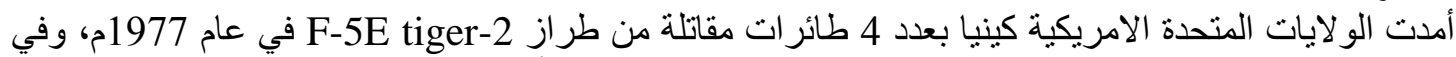

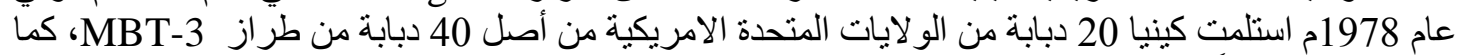

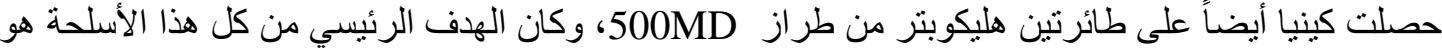

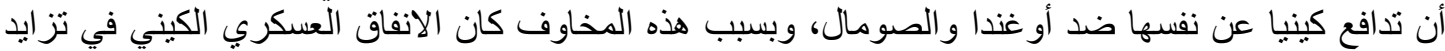
مستمر فوصل في عام 1976م نحو 110 مليون دو لار، وبلغ الانفاق العسكري الكيني في عام 1978م العان نحو 240

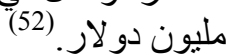
أما عن التدريبات والدساعدات العسكرية من الولايات المتحدة الامريكية لكينيا، فهو من أحد أهم أهداف سياسة

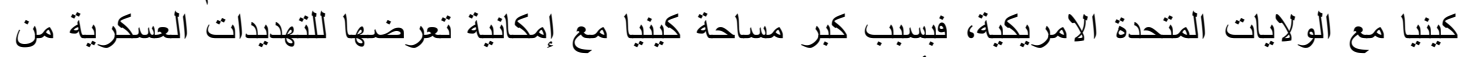

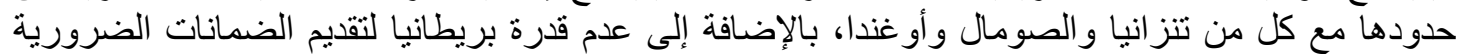

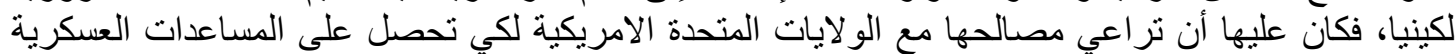

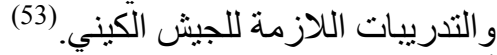

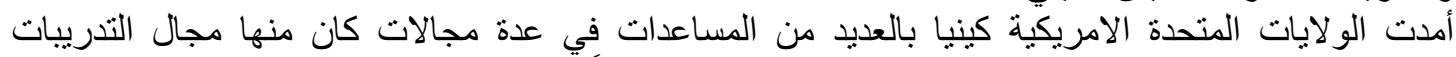

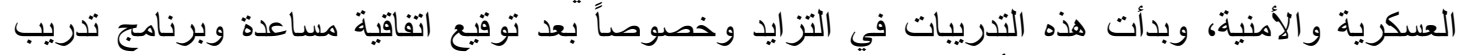

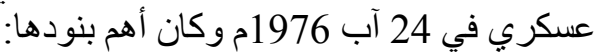
1- لن تسمح الو لايات الامريكية بدون مو افقتها باستخدام هذه البر امج و والمساعدات بو اسطة أب شخص لا يكون

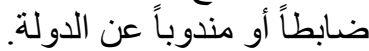

2- أن تسمح الحكومة الكينية لموظفي الحكومة الامريكية بمر اجعة مستمرة ومتابعة استخدام تلكابك المساعدات.

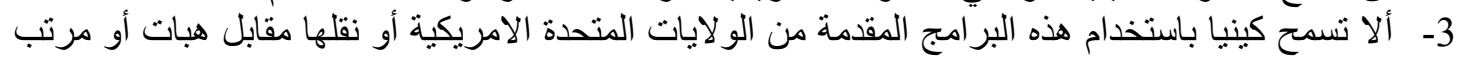
أو أب مقابل آخر. 4- ألا تستخدم كينيا هذه البرامج لأي أغراض غير المتفق عليها مع الحكومة الامريكية.

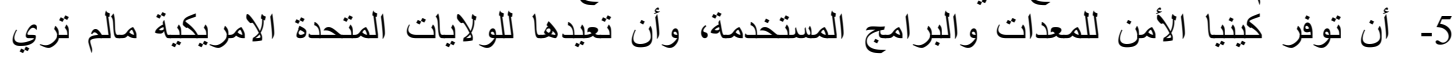

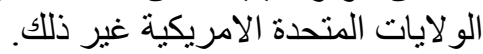
وقد جاءت هذه الاتفاقية في عام 1976م ولاتير هو نفس العام الذي شهد تحركاً عسكرياً أمريكياً مكثناً تجاه كينيا، كما

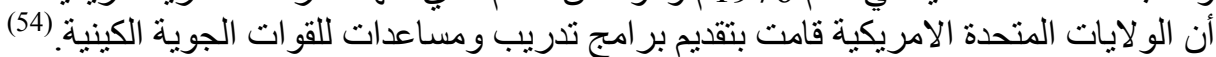

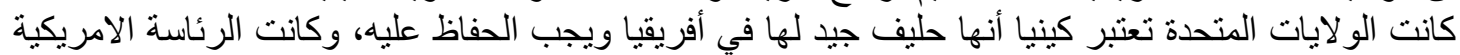

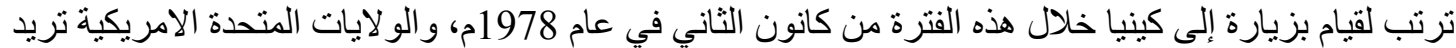

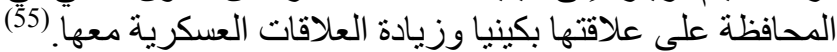

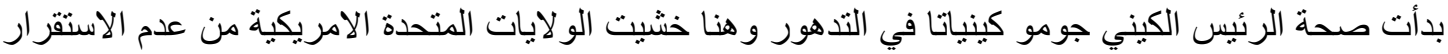

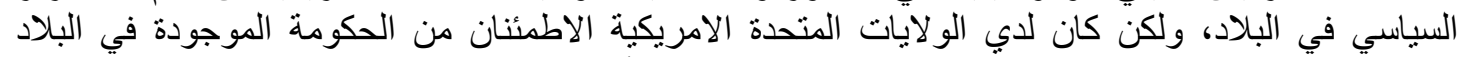

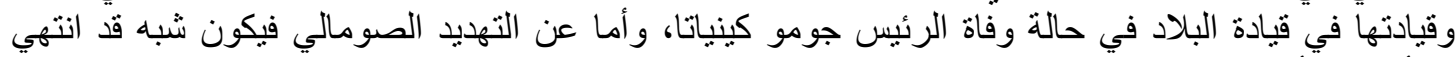

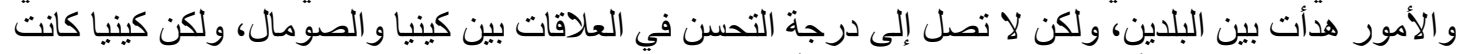
تخشي التهديد الاثيوبي أكثر في الوقت الحالي، وأما عن السؤدان فكانت علاقة كينيا بالسودان في هذه الفنترة 


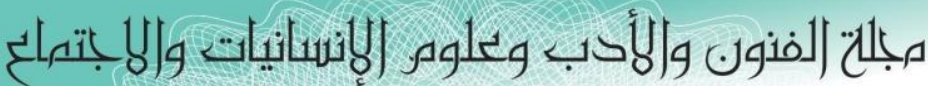

Journal of Arts, Literature, Humanities and Social Sciences

ISSN online: 2414 - 3383

ISSN print: 2616 - 3810

\section{ايلول - سبتمبر 2019}

العدد (43)

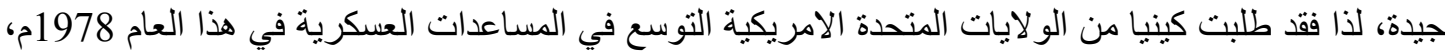

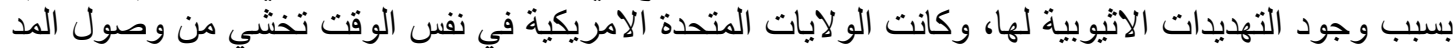

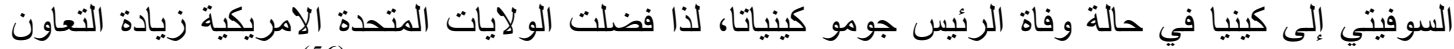

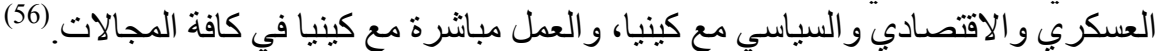

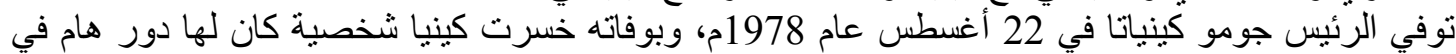

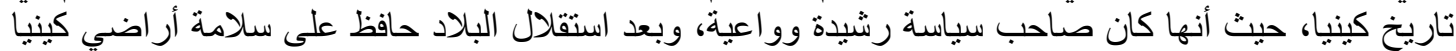

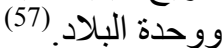
حقق الرئيس جومو كينياتا الكثير لكينيا، من حيث كافة النواحي الاقتصادية و العسكرية و السياسية، وبوفاته تبدأ مرحلة جديدة من العلاقات الامريكية الكينية على كافة المستويات و المجالات.

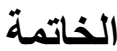

وفي نهاية البحث وخاتمته يتضح أن العلاقات الامريكية الكينية علاقات تمتد منذ زمن حتى قبل حصول كينيا

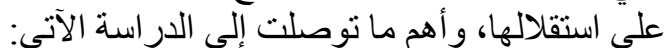

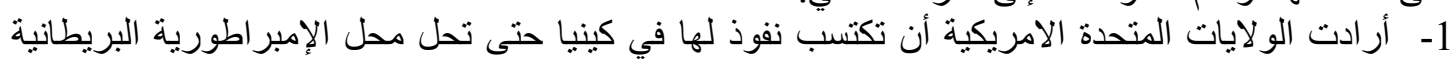
المتهاوية في شرق الفريقيا. 2- كان لتوجه الو لايات المتحدة الامريكية نحو كينيا بو اعث استر اتيجية واقتصادية وسياسية جعلتها تتوجه نحو

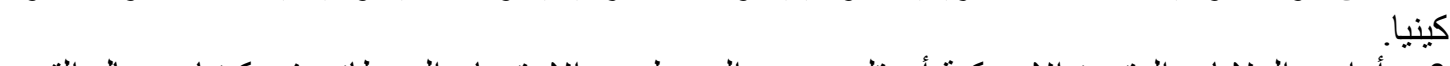
3- أرادت الولايات المتحدة الامريكية أن تلعب دور الوسيط بين الاستعمار البريطاني في كينيا ورجال القوي

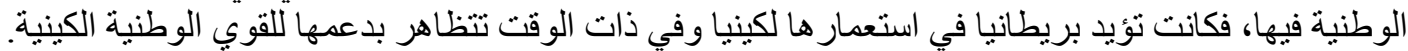

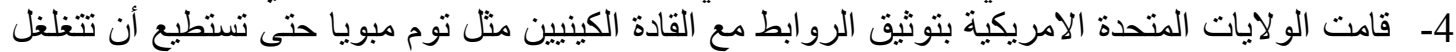

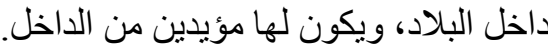

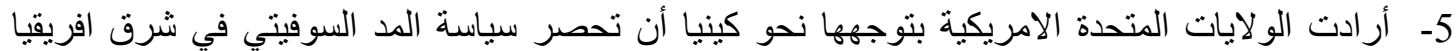

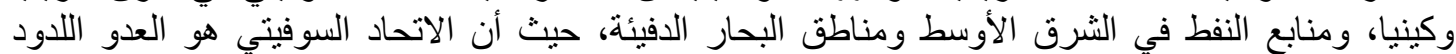
ل اللو لايات المتحدة الامريكية. 6- استطاعت الو لايات المتحدة الامريكية بسياستها الاقتصادية و السياسة و العسكرية أن تجعل رئيس الدولة وهو

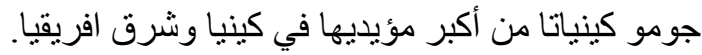

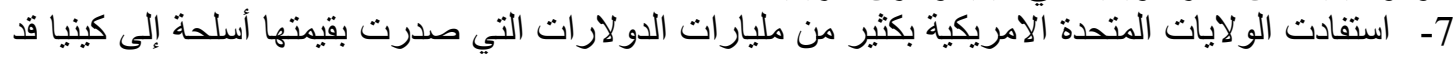

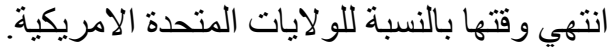
8- استطاعت الولايات المتحدة الامريكية أن تستفيد من علاقاتها مع كينيا بالحصول على العديد من المو اد الخام

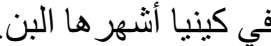
9- حاولت الو لايات المتحدة الامريكية التغلغل في كينيا عن طريق عدة طرق كان أهمها المنح الدراسية وقد نجحت في تحقيق ذلك.

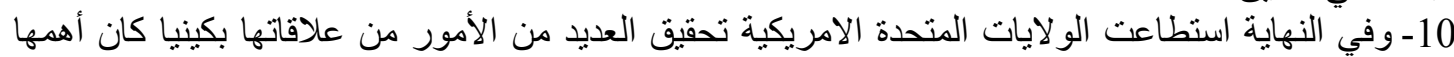

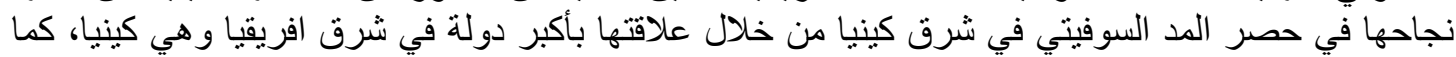

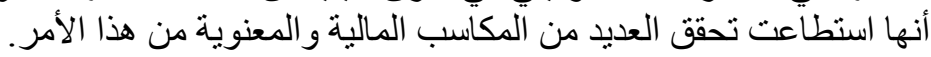

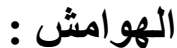

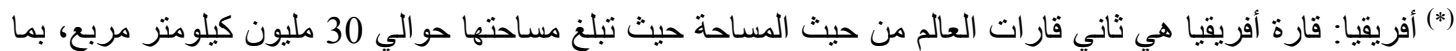

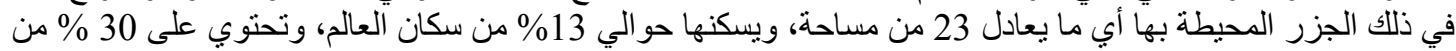

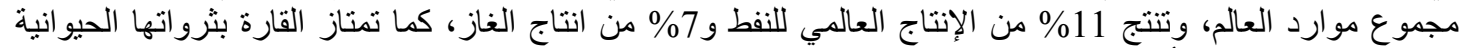

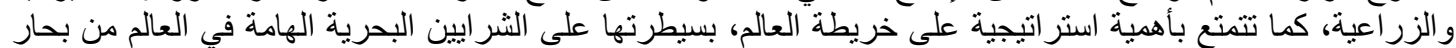




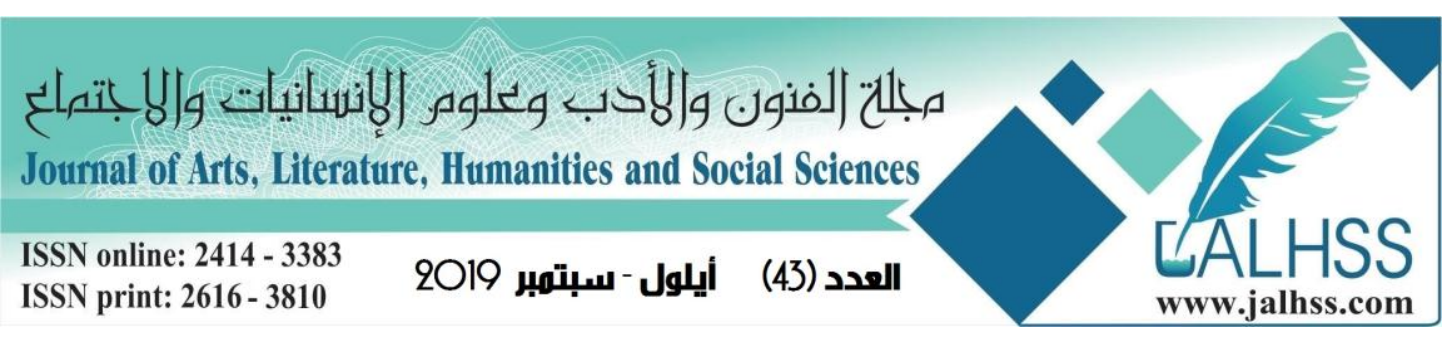

ومحيطات وممر ات مائية، هذا بالإضافة إلى توسطها قار ات العالم و التحكم في المو اصلات البحرية و البرية و الجوية بين

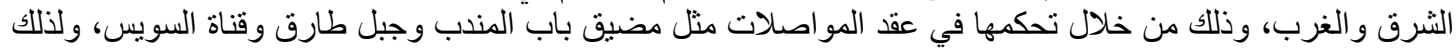

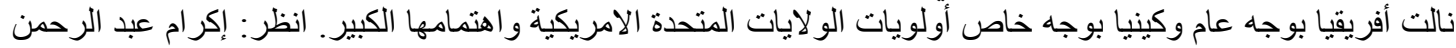

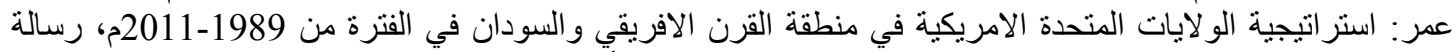

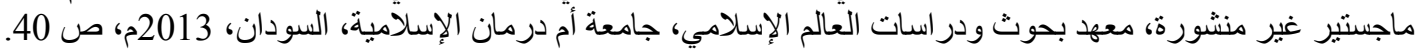

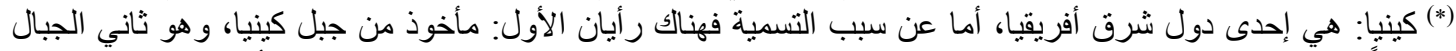

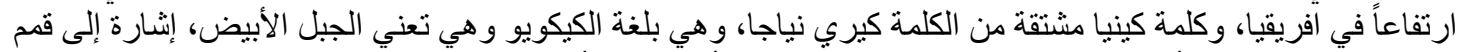

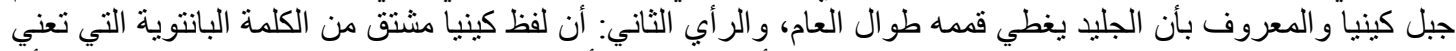

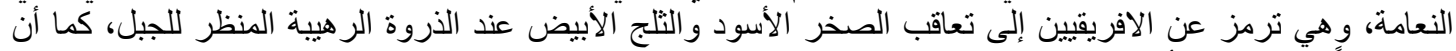

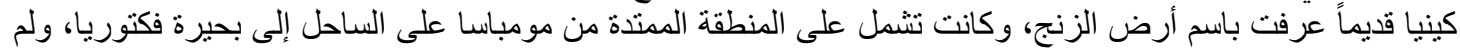

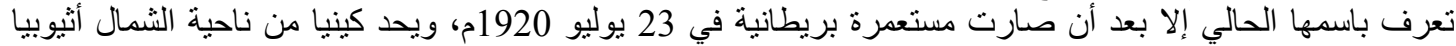

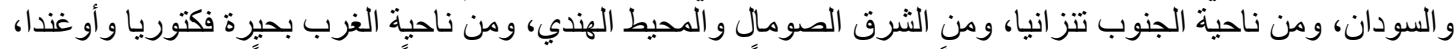

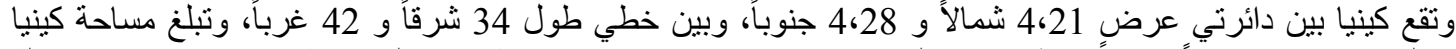

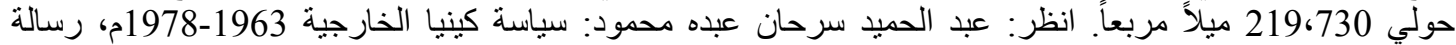

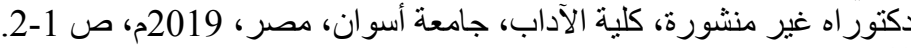

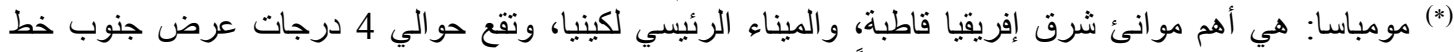

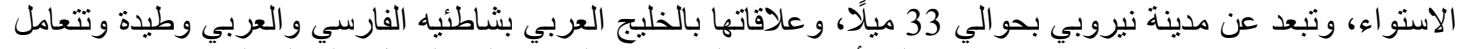

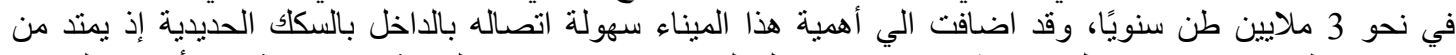

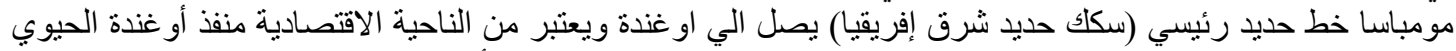

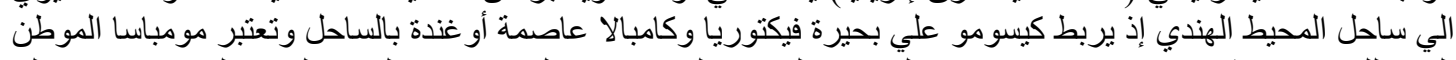

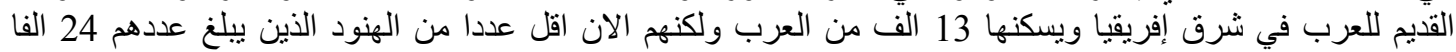

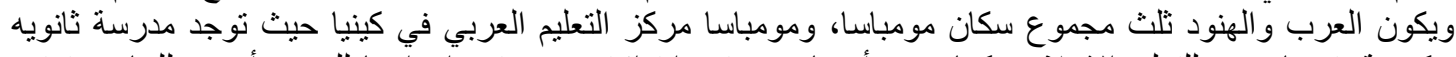

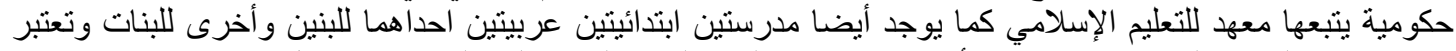

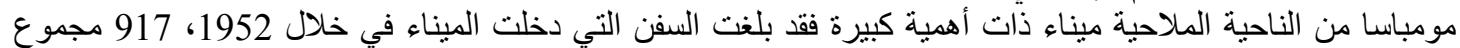

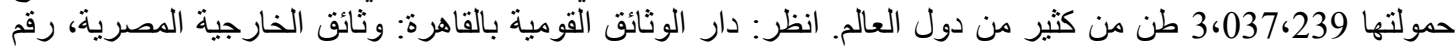

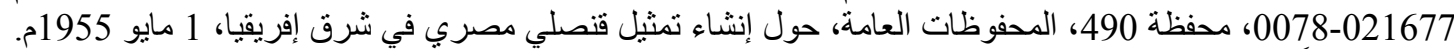
؛ انظر أيضاً: محمد عبد الغني سعودي: أفريقية في شخصية القارة وشخصية الأقاليم، مكتبة الأنجلو المصرية، القاهرة،

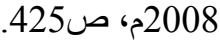

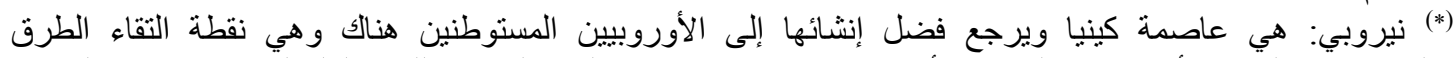

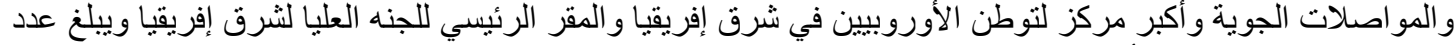

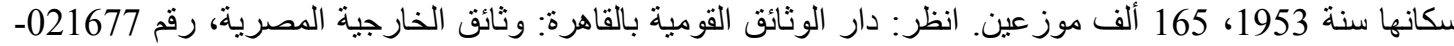

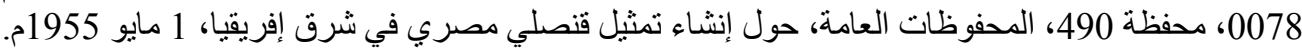

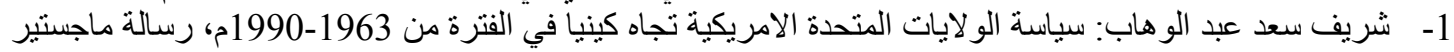

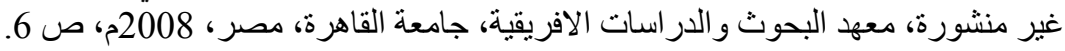
2- Peter Marris: the African entrepreneur, African publishing corporation, New York, 1972, pp.10-12.

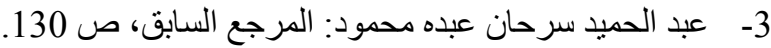

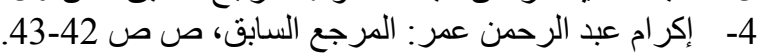

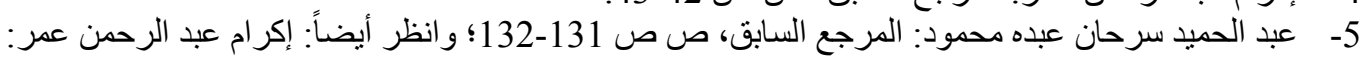

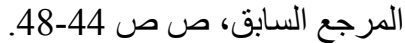

6- Okoth Pontian Godfrey: united states policy toward Kenya 1952-1969, PhD, university of California, Los Angeles, 1987, p.12.

7- عبد الحميد سرحان عبده محمود: المرجع السابق، ص ص 132.

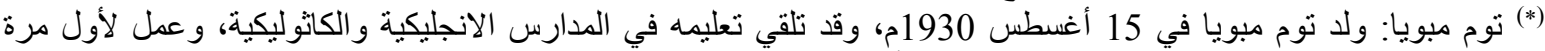
كمفت صحي في نيروبي، ثم التحق باتحاد العمال وأصبح السكرتير العام لاتحاد نقابات العمال في كينيا، ، وقد ذهب في في العام 


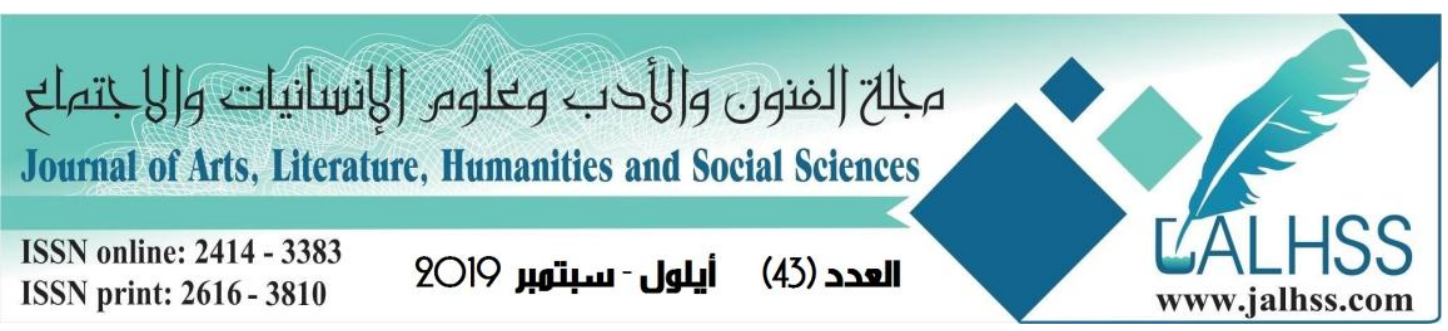

1955م في بعثة در اسية لجامعة اسكفورد لدر اسة العلاقات الصناعية، وقد انخرط في الحركة الوطنية الكينية، وكان توم مبويا شخصية وطنية، وقد فاز في انتخابات المجلس التشريعي لعام 1957م كمرشح عمال، ليصبح واحدًا من ثمانية أعضاء أفياء أفارفة

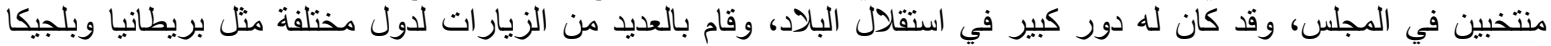

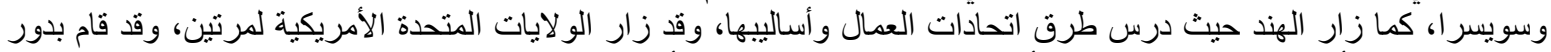

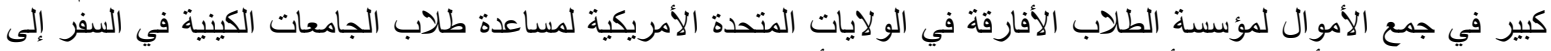

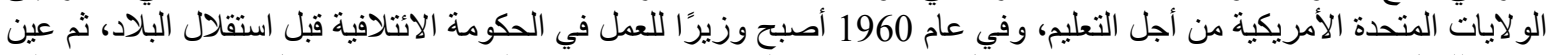

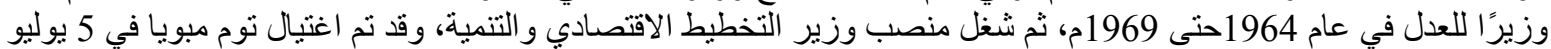

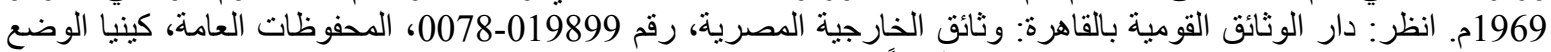

https://www.britannica.com/biography/Tom-Mboya

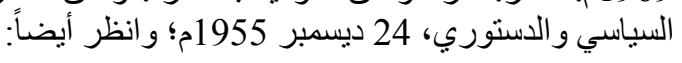

(*) جومو كينياتا: ولد جومو كينياتا في 1890م في مدينة كيامبو (Kiambo)، وقد اعتنق المسيحية وعُمِد وأطلقت عليه

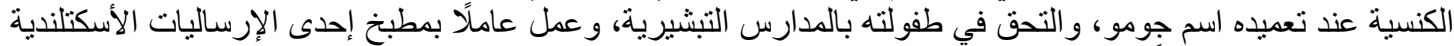

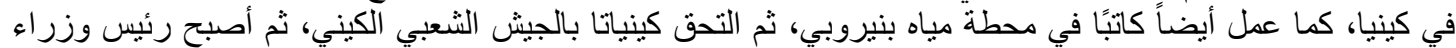

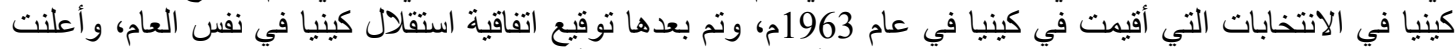

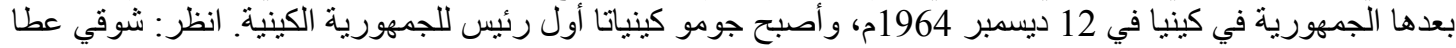

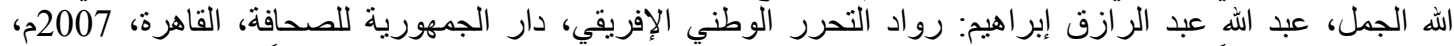

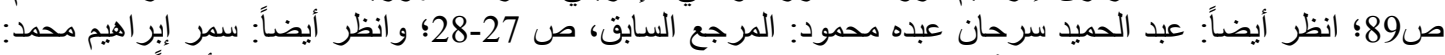

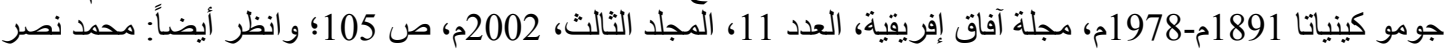

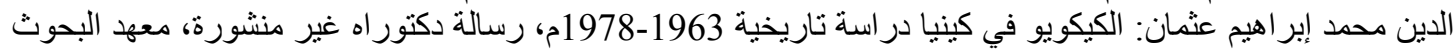

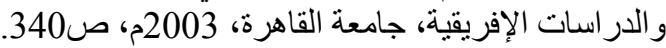

C.A.B.128/ 35/61, Kenya, Jomo Kenyatta, Cabinet Office, S.W.I, 3, Oct.1963.

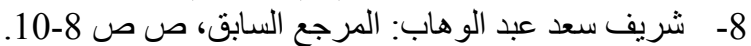

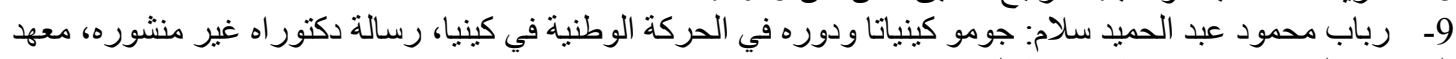

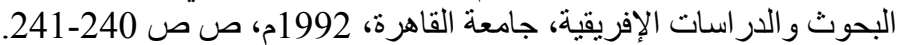

10- White House Central Files: FO 2/CO 142-CO 150, memorandum for the president, New Letter of Credence for Ambassador William Attwood, Averell Harriman Acting Secretary, 2, Dec. 1964.

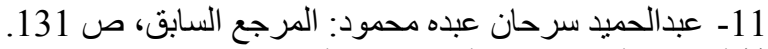

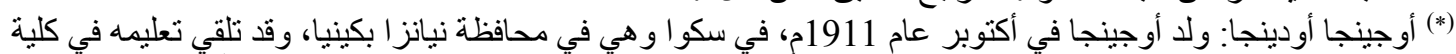

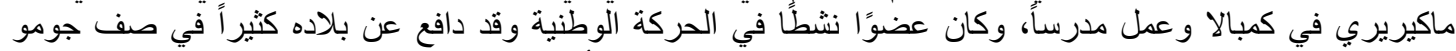

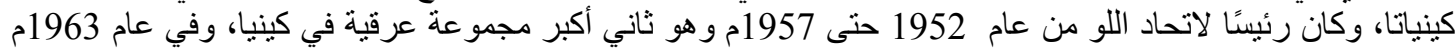

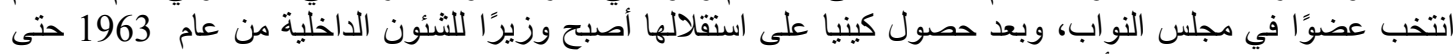

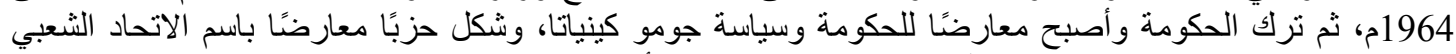

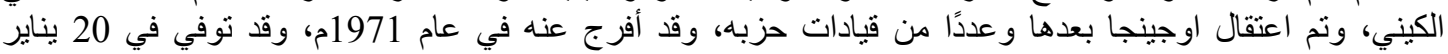

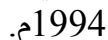

https://www.britannica.com/biography/Oginga-Odinga

12- Norman N. Miller: Kenya, The Quest for prosperity, Westview Press, London, 1990, pp. 135-138.

13- Okoth Pontian Godfrey: op. cit., p.181.

14- محمد عيسي الثرقاوي: الخريطة السياسية في كينيا بعد كينياتا، مجلة السياسة الدولية، مصر ، العدد 55، 1979م،

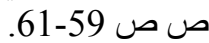

(*) ليندون باينس جونسون: هو الرئيس السادس و الثنلاتون للو لايات المتحدة الامريكية، ولد في 28 أغسطس عام 1908م، وكان

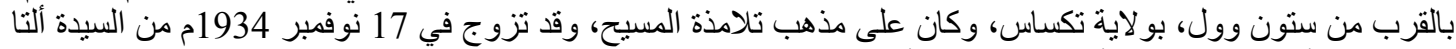
تايلور، وقد أنجب اثنين من الأولاد، وكان من أنصار الحزب الديموقر اطي، وقد تولي رئاسة الو لايات المتحدة الامريكية في ترون 
مبلحت (لفنون والأذب وعلوهر الإنسانيات والبانتمالع

Journal of Arts, Literature, Humanities and Social Sciences

ISSN online: 2414 - 3383

ISSN print: 2616 - 3810

أيلول - سبتمبر 2019

العدد (43)

22 نوفمبر عام 1963م حتى 20 يناير عام 1969م، وقد توفي في 22 يناير عام 1973م. انظر: أودو زاوتر : رؤساء

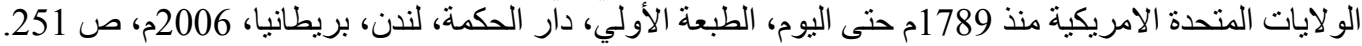

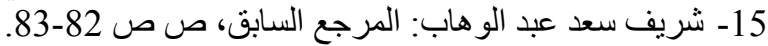

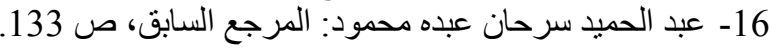

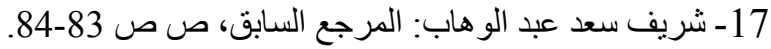

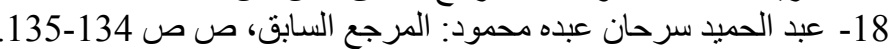

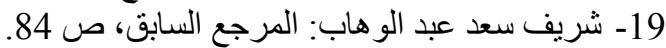

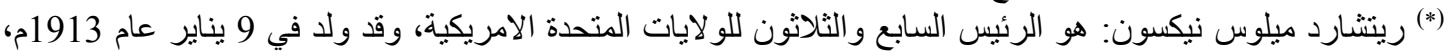

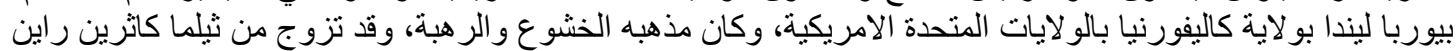

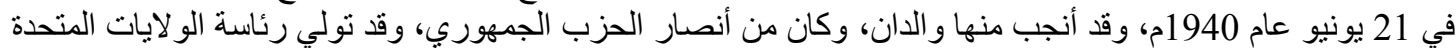

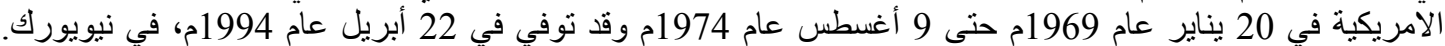

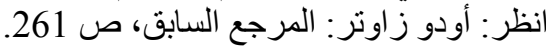

20- White House: No.35/5, President Richard M. Nixon's letter to Kenyan President Jomo Kenyatta expresses hope that Secretary of State William Roger's trip to Kenya will solidify U.S.-Kenyan relations, 6, Feb. 1970.

21 - شريف سعد عبد الوهاب: المرجع السابق، ص صد 85.

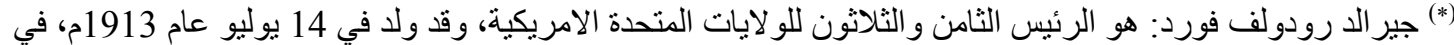

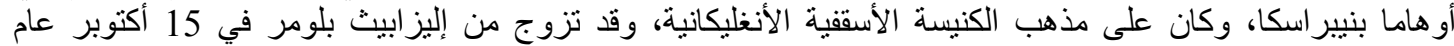

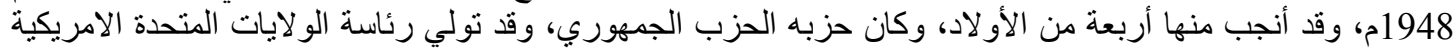

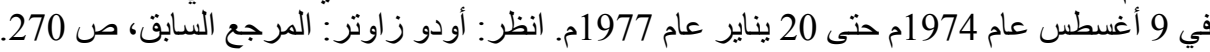

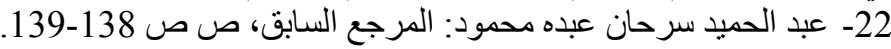

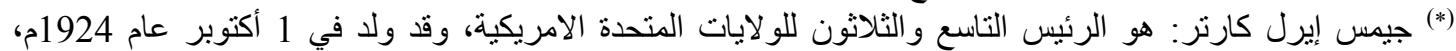

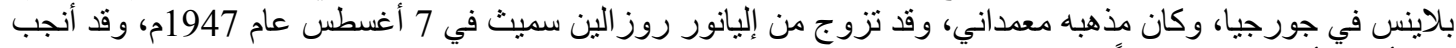

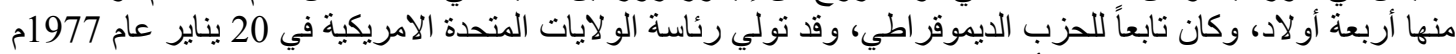

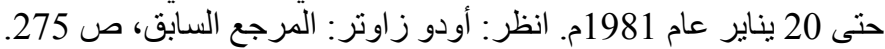
23- شريف سعد عبد الو هاب: المرجع السابق، صن :

24- Maria Nzomo: The foreign policy of Kenya and Tanzania: the impact of dependence and underdevelopment, PhD, Dalhousie University, 1982, p.430.

25- Maria Nzomo: Ibid., p.431.

26- Bosire R. Moegi: Kenya-U.S. relations, an interplay of national 1963-1991, M.A, university of Nairobi, 1993, pp.168-170.

28- Bosire R. Moegi: op. cit., pp. 39-40.

27- شريف سعد عبد الوهاب: المرجع السابق، ص 44.

29- رؤوف راشد خله: كينيا دراسة في الجغرافيا السياسية، رسالة ماجستير غير منشورة، معهد البحوث والدراسات

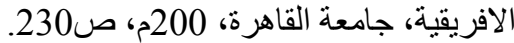

30- Maria Nzomo: op. cit., pp.430-431.

31- أندريه أوزادوفسكي: الو لايات المتحدة الأمريكية وافريقيا، ترجمة عماد حاتم، أمانة البحث العلمي، مركز البحوث

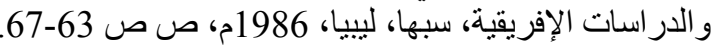

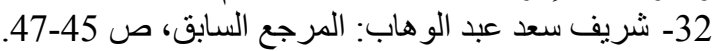

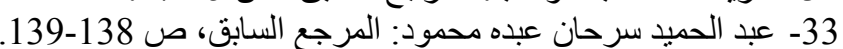

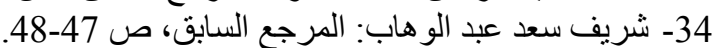

35- Philip O.Nyinguro: United State and the transition to democracy in Kenya 1990-1992,

M.S,University of Nairobi, Kenya, 1990, p.p, 189-190.

37- Philip O.Nyinguro: op. cit., p.191.

36- شريف سعد عبد الوهاب: المرجع السابق، ص 51-52. 


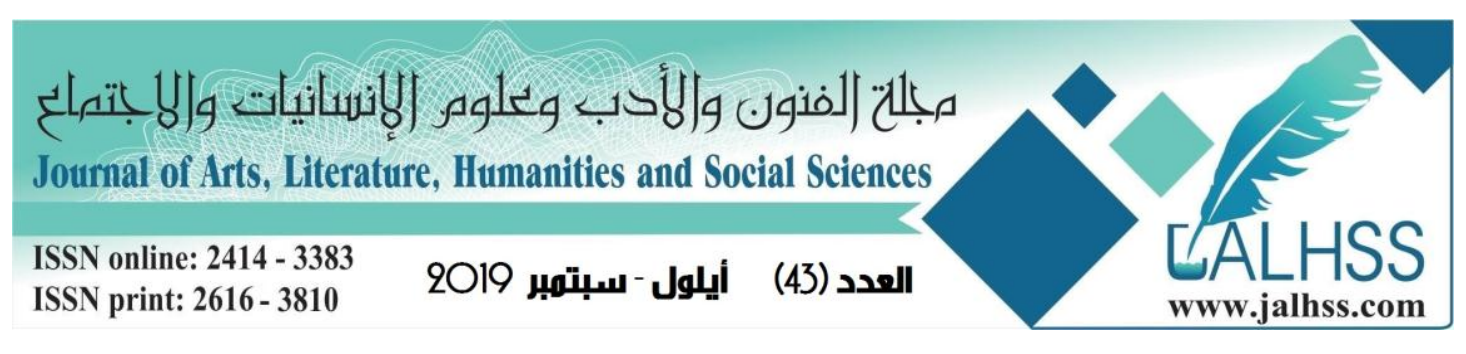

39- Philip O.Nyinguro: op. cit., p.p173-191.

$$
\text { 38- شريف سعد عبد الو هاب: المرجع السابق، ص 52-53. }
$$

40- شريف سعد عبد الو هاب: المرجع السابق، ص 124. 124.

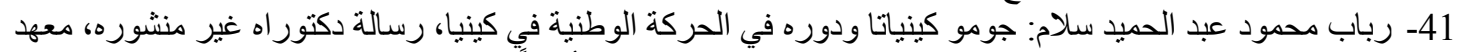

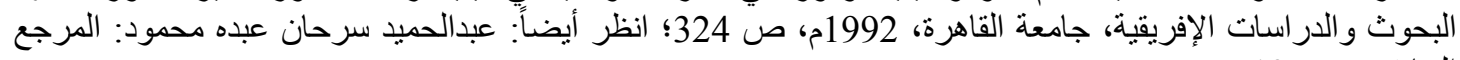

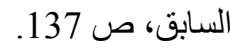

42- شريف سعد عبد الو هاب: المرجع السابق، ص 124.

43- White House: James T. Lynn recommends Ford sign a Presidential Determination authorizing provision of sophisticated weapons systems to Ethiopia and Kenya, 24, June. 1975.

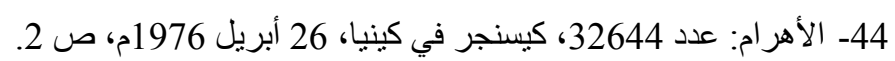

45- Daily Telegraph: U.S. Defence Secretary for Kenya and Zaire, our Washington Staff, p.4, 14, June. 1976.

46- Flora Lewis: Rumsfeld to Discuss Military Aid with Kenya, Zaire on African Trip, International Herald Tribune, p.1, 15, June. 1976..

47- National Security Council: Deputy Secretary of State Ingersoll recommends President Ford make Presidential Determination to allow F-5A/B aircraft to be furnished to Ethiopia and Kenya on a grant and credit basis, Secretary Kissinger, 27, June. 1975.

48- The Times: America to supply planes worth $£ 44 m$ to Kenya, p.8, 17, June. 1976.

Samuel M. Makinda: Super power diplomacy in the horn of Africa, st. martin's press, New York, 1987, pp.99-101.

49- State Department: Telegrams from SECSTATE - EXDIS, planned arrival of P 3 aircraft and of frigate, MS Ford Administration and Foreign Affairs, July. 1976.

$$
\text { 50- عبدالحميد سرحان عبده محمود: المرجع السابق، ص } 139 \text {. Wapr, } 139 .
$$

51- International Herald Tribune: Kenya Receives Shipment of U.S. Warplanes, 12, Apr, 1978, p.1.

$$
\text { 52- شريف سعد عبد الوهاب: المرجع السابق، ص } 126 .
$$

53- Siman Baynham: Military power and politics in black Africa, st. Martin's press, New York, 1986, p.245-247.

$$
\text { 54- شريف سعد عبد الو هاب: المرجع السابق، ص ص 121-122. }
$$

55- National Security Council: Memo from Paul B. Henze to Zbigniew Brzezinski concerning President Carter's visit to Africa. Reasons for and against visits to Kenya, Sudan, and Tanzania are discussed, 11, Jan. 1978.

56- National Security Council: Memorandum for Zbigniew Brzezinski from Paul B. Henze regarding the situation in the Horn of Africa, Topics include: political situation in Ethiopia; Cuban involvement in the Ogaden; deteriorating health and mental conditions in Kenya; Eritrea independence struggle, 27, July. 1978.

57- شوقي عطا اله الجمل، عبد الله عبد الرازق إبراهيم: رواد التحرر الوطني الإفريقي، دار الجمهورية للصحافة،

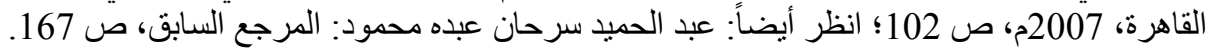




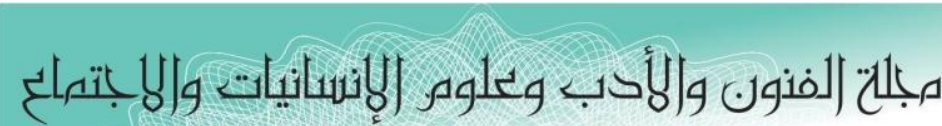 \\ Journal of Arts, Literature, Humanities and Social Sciences}

ISSN online: 2414 - 3383

ISSN print: 2616 - 3810

أيلول - سبتمبر 2019

العدد (43)
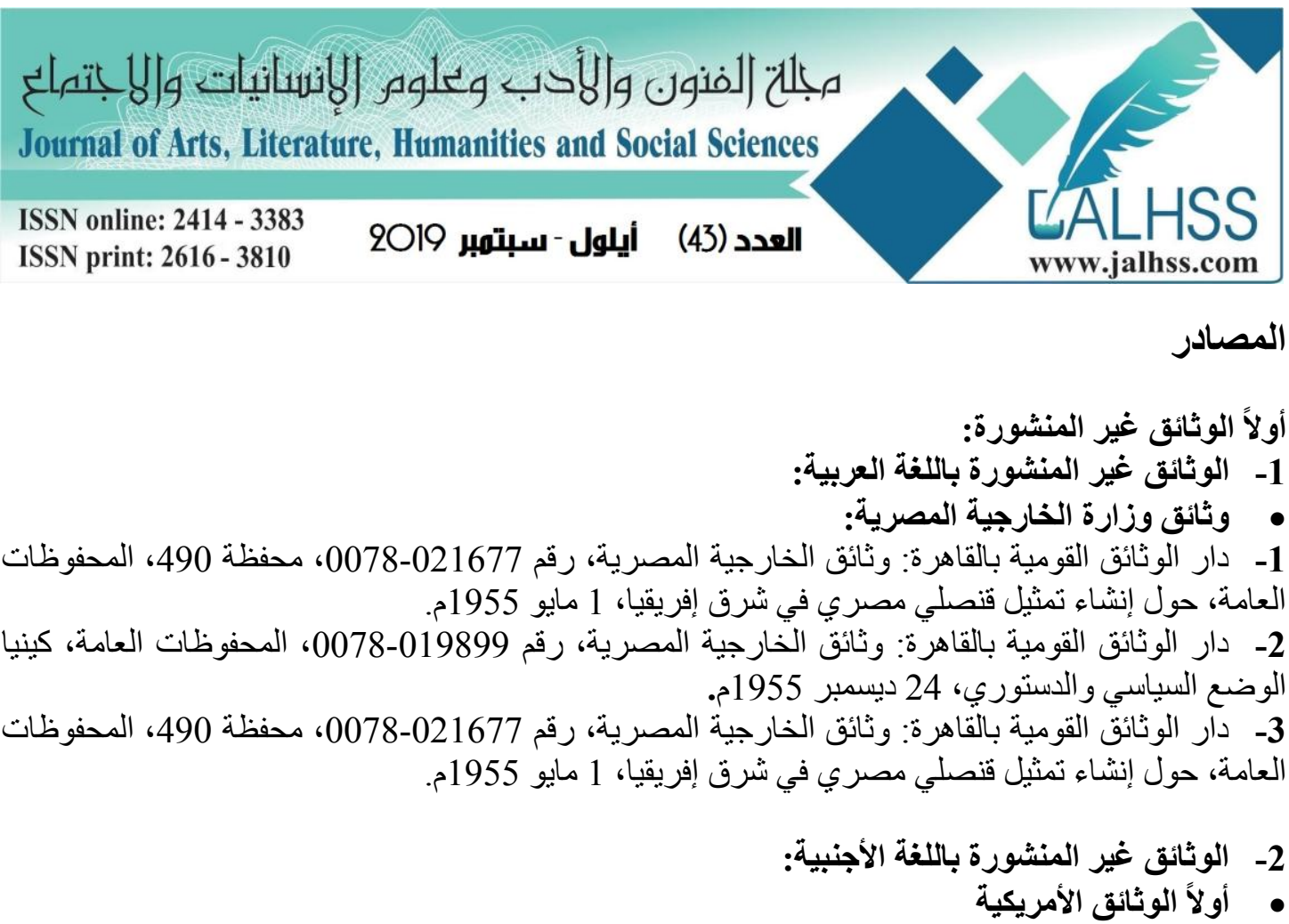

\section{White House}

1- White House Central Files: FO 2/CO 142-CO 150, memorandum for the president, New Letter of Credence for Ambassador William Attwood, Averell Harriman Acting Secretary, 2, Dec. 1964.

2- White House: No.35/5, President Richard M. Nixon's letter to Kenyan President Jomo Kenyatta expresses hope that Secretary of State William Roger's trip to Kenya will solidify U.S.-Kenyan relations, 6, Feb. 1970.

3-White House: James T. Lynn recommends Ford sign a Presidential Determination authorizing provision of sophisticated weapons systems to Ethiopia and Kenya, 24,

\section{National Security Council}

June. 1975.

1-National Security Council: Deputy Secretary of State Ingersoll recommends President Ford make Presidential Determination to allow F-5A/B aircraft to be furnished to Ethiopia and Kenya on a grant and credit basis, Secretary Kissinger, 27, June. 1975.

\section{State Department}

1- State Department: Telegrams from SECSTATE - EXDIS, planned arrival of P 3 aircraft and of frigate, MS Ford Administration and Foreign Affairs, July. 1976.

\section{National Security Council}

1- National Security Council: Memorandum for Zbigniew Brzezinski from Paul B. Henze regarding the situation in the Horn of Africa, Topics include: political situation in Ethiopia; Cuban involvement in the Ogaden; deteriorating health and mental conditions in Kenya; Eritrea independence struggle, 27, July. 1978. 


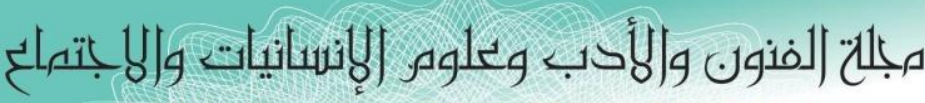

Journal of Arts, Literature, Humanities and Social Sciences

ISSN online: 2414 - 3383

ISSN print: 2616 - 3810

أيلول - سبتهبر 2019

العدد (43)

\section{Colonial Office}

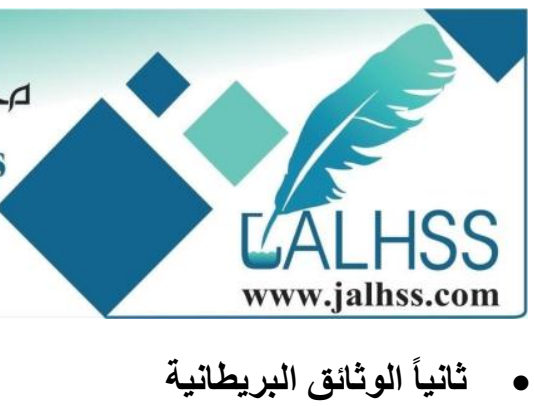

1-CO 1047/140, The Colony and Protectorate of Kenya, Kew, United Kingdom, 1924-1925.

2- C.A.B.128/ 35/61, Kenya, Jomo Kenyatta, Cabinet Office, S.W.I, 3, Oct.1963.

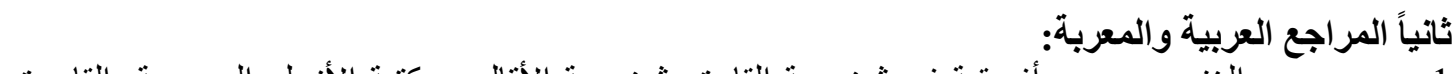
1- محد عبد الغني سعودي: أفريقية في شخصية القارة وشخصية الأقاليم، مكتبة الأنجلو المصرية، القاهرة، 2008 2- شوفي عطا الله الجمل، عبد الله عبد الرازق إبراهيم: رواد التحرر الوطني الإفريقي، دار الجمهورية

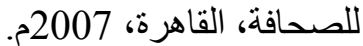

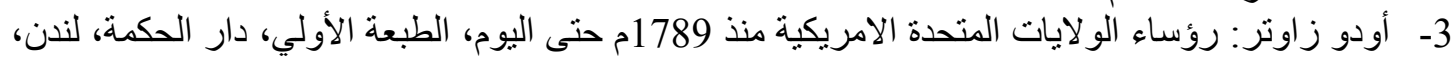

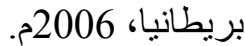
4- أندريه أوز ادوفسكي: الو لايات المتحدة الأمريكية وافريقيا، ترجمة عماد حاتم، أمانة البحث العلمي، مركز

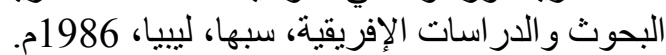

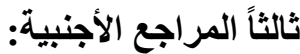
1-Peter Marris: the African entrepreneur, African publishing corporation, New York, 1972.

2- Norman N. Miller: Kenya, The Quest for prosperity, Westview Press, London, 1990.

3- Samuel M. Makinda: Super power diplomacy in the horn of Africa, st. martin's press, New York, 1987.

4- Siman Baynham: Military power and politics in black Africa, st. Martin's press, New York, 1986.

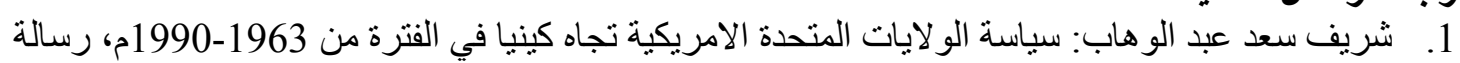

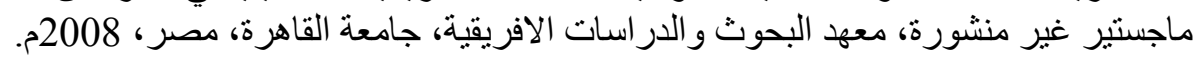

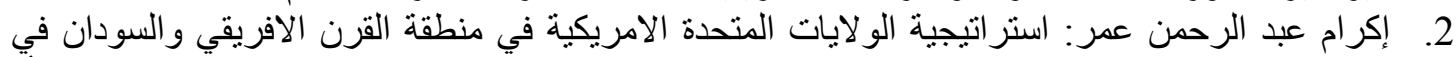

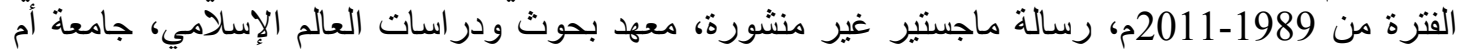
درمان الإسلامية، السودان، 2013م.

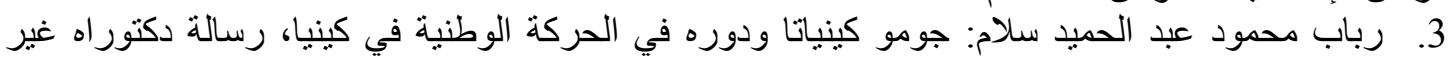

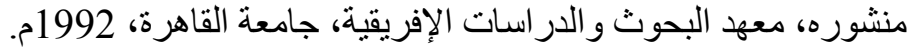
4. رؤوف راثد خله: كينيا دراسة في الجغرافيات الإنة السياسية، رسالة ماجستير غير منشورة، معهد البحوث و الدر اسات الافريقية، جامعة القاهرة، 200 200م.

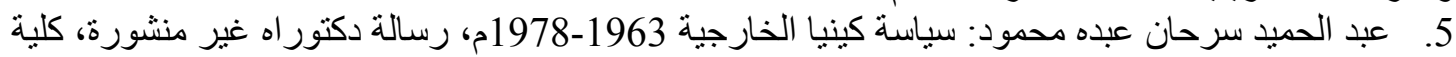

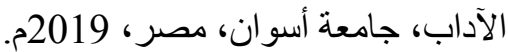

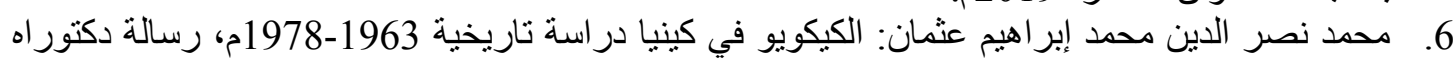
غير منشورة، معهد البحوث و الدر اسات الإفريقية، جامعة القاهرة، 2003م.

7- Bosire R. Moegi: Kenya-U.S. relations, an interplay of national 1963-1991, M.A, university of Nairobi, 1993. 


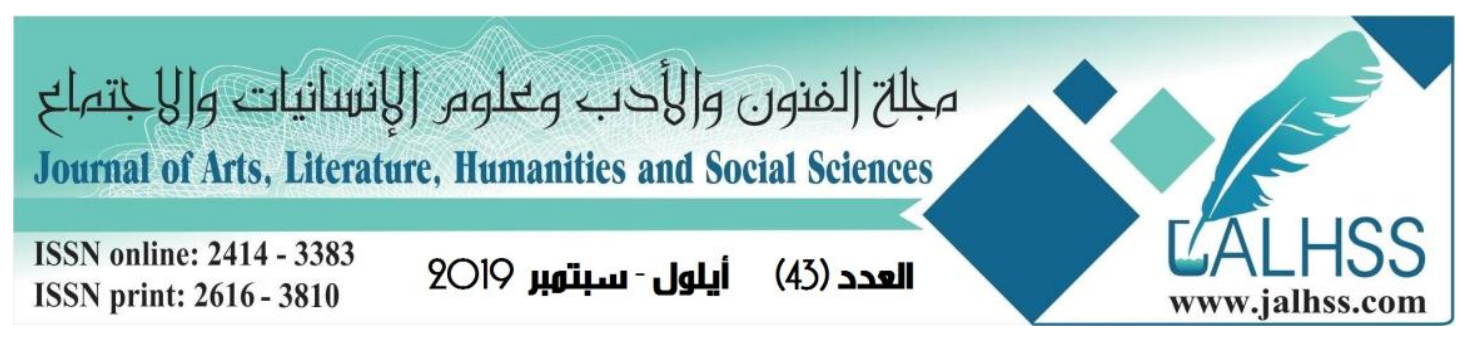

8- Philip O.Nyinguro: United State and the transition to democracy in Kenya 19901992, M.S,University of Nairobi, Kenya, 1990.

9-Okoth Pontian Godfrey: united states policy toward Kenya 1952-1969, PhD, university of California, Los Angeles, 1987.

10- Maria Nzomo: The foreign policy of Kenya and Tanzania: the impact of dependence and underdevelopment, PhD, Dalhousie University, 1982.

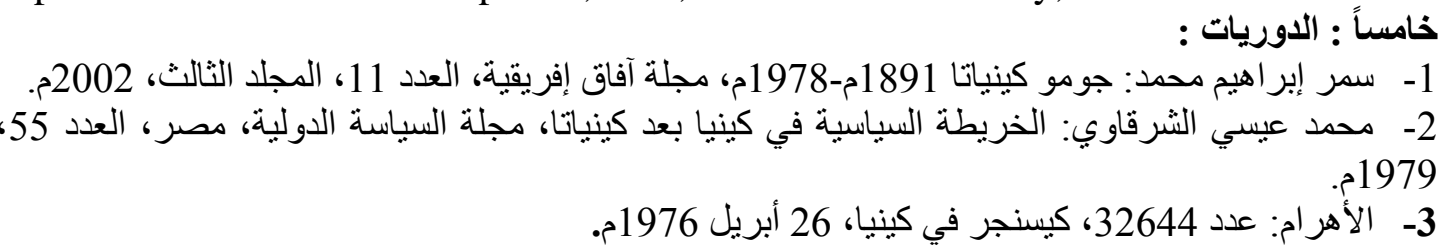

4- Daily Telegraph: U.S. Defence Secretary for Kenya and Zaire, our Washington Staff, p.4, 14, June. 1976.

5- Flora Lewis: Rumsfeld to Discuss Military Aid with Kenya, Zaire on African Trip, International Herald Tribune, p. 1, 15, June. 1976.

6-The Times: America to supply planes worth £44m to Kenya, p.8, 17, June. 1976.

7-International Herald Tribune: Kenya Receives Shipment of U.S. Warplanes, 12, Apr, 1978.

1-https://www.britannica.com/biography/Tom-Mboya

سادساً شبكة الانترنت الدولية

2-https://www.britannica.com/biography/Oginga-Odinga

\section{References}

1. National Archives of Egypt: The Egyptian Foreign Documents, No. 0216770078, Portfolio 490, Public Archives, on the Establishment of an Egyptian Consular Representation in East Africa, May 1, 1955.

2. National Archives of Cairo: Egyptian Foreign Documents, No. 019899-0078, Public Archives, Kenya Political and Constitutional Status, 24 December 1955.

3. National Archives of Egypt: The Egyptian Foreign Documents, No. 0216770078, Portfolio 490, Public Archives, on the Establishment of an Egyptian Consular Representation in East Africa, May 1, 1955.

4. White House Central Files: FO 2 / CO 142-CO 150, memorandum for the president, New Letter of Credence for Ambassador William Attwood, Averell Harriman Acting Secretary, 2, Dec. 1964.

5. White House: No.35 / 5, President Richard M. Nixon's letter to Kenyan President Jomo Kenyatta expresses hope that Secretary of State William Roger's trip to Kenya will solidify U.S.-Kenyan relations, 6, Feb. 1970. 


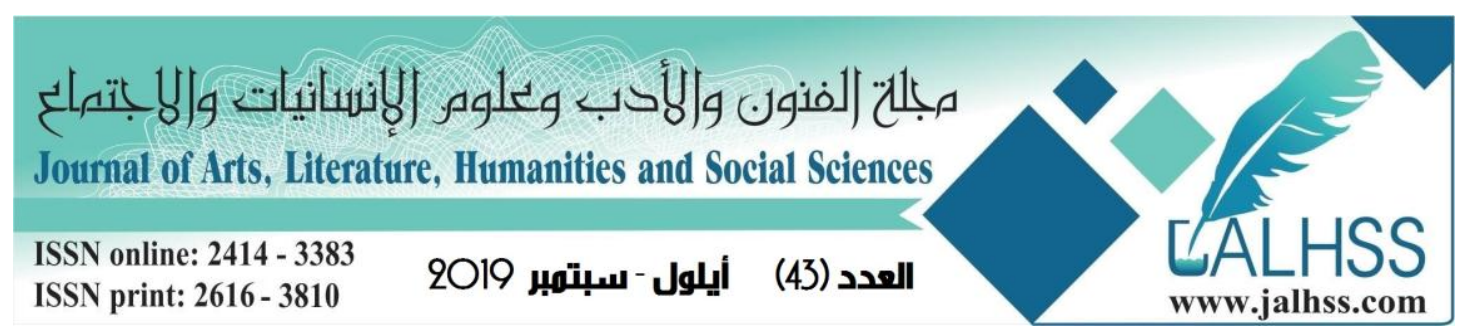

6. White House: James T. Lynn recommends Ford sign a Presidential Determination authorizing provision of sophisticated weapons systems to Ethiopia and Kenya, 24, June. 1975.

7. National Security Council: Deputy Secretary of State Ingersoll recommends President Ford make Presidential Determination to allow F-5A / B aircraft to be furnished to Ethiopia and Kenya on a grant and credit basis, Secretary Kissinger, 27, June. 1975.

8. State Department: Telegrams from SECSTATE - EXDIS, planned arrival of $P$ 3 aircraft and of frigate, MS Ford Administration and Foreign Affairs, July. 1976. National Security Council: Memorandum for Zbigniew Brzezinski from Paul B. Henze regarding the situation in the Horn of Africa, Topics include: political situation in Ethiopia; Cuban involvement in the Ogaden; deteriorating health and mental conditions in Kenya; Eritrea independence struggle, 27, July. 1978.

9. CO 1047/140, The Colony and Protectorate of Kenya, Kew, United Kingdom, 1924-1925.

10. C.A.B.128 / 35/61, Kenya, Jomo Kenyatta, Cabinet Office, S.W.I, 3, Oct.1963.

11. Mohammed Abdul Ghani Saudi: African in the personality of the continent and the personality of the regions, the Anglo-Egyptian Library, Cairo, 2008.

12. Shawki Atallah El-Gamal, Abdallah Abdel-Razek Ibrahim: Pioneers of African National Liberation, Gomhouria Press House, Cairo, 2007.

13. Udo Zauter: Presidents of the United States of America since 1789 until today, the first edition, House of Wisdom, London, Britain, 2006.

14. Andrei Ozadowski: USA and Africa, translated by Emad Hatem, Secretariat of Scientific Research, Center for African Research and Studies, Sabha, Libya, 1986.

15. Peter Marris: the African entrepreneur, African publishing corporation, New York, 1972.

16. Norman N. Miller: Kenya, The Quest for prosperity, Westview Press, London, 1990.

17. Samuel M. Makinda: Super power diplomacy in the horn of Africa, st. martin's press, New York, 1987.

18. Siman Baynham: Military power and politics in black Africa, st. Martin's press, New York, 1986.

19. Sherif Saad Abdel Wahab: United States Policy towards Kenya from 19631990, Unpublished Master Thesis, Institute of African Research and Studies, Cairo University, Egypt, 2008.

20. Ikram Abdul Rahman Omar: US Strategy in the Horn of Africa and Sudan from 1989-2011, Unpublished Master Thesis, Islamic World Research and Studies Institute, Omdurman Islamic University, Sudan, 2013. 


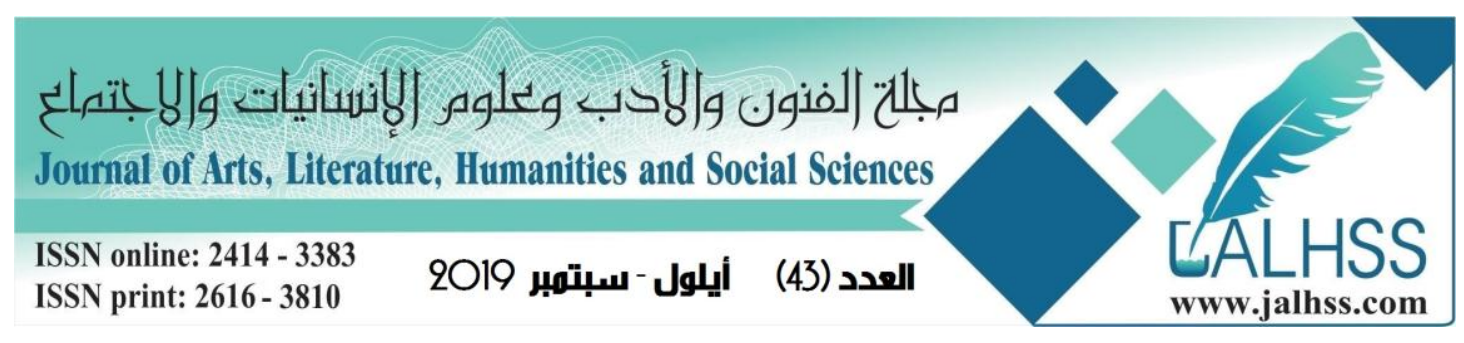

21. Rabab Mahmoud Abdel Hamid Salam: Jomo Kenyatta and his role in the national movement in Kenya, unpublished doctoral thesis, Institute of African Research and Studies, Cairo University, 1992.

22. Raouf Rashed Khalle: Kenya Study in Political Geography, Unpublished Master Thesis, Institute of African Research and Studies, Cairo University, 200 AD.

23. Abdul Hamid Sarhan Abdo Mahmoud: Kenya's Foreign Policy 1963-1978, unpublished doctoral thesis, Faculty of Arts, Aswan University, Egypt, 2019.

24. Mohamed Nasr Eldin Mohamed Ibrahim Osman: Kikuyu in Kenya, a historical study 1963-1978, unpublished doctoral thesis, Institute of African Research and Studies, Cairo University, 2003.

25. Bosire R. Moegi: Kenya-U.S. relations, an interplay of national 1963-1991, M.A, university of Nairobi, 1993.

26. Philip O.Nyinguro: United State and the transition to democracy in Kenya 1990-1992, M.S, University of Nairobi, Kenya, 1990.

27. Okoth Pontian Godfrey: united states policy toward Kenya 1952-1969, PhD, university of California, Los Angeles, 1987.

28. Maria Nzomo: The foreign policy of Kenya and Tanzania: the impact of dependence and underdevelopment, PhD, Dalhousie University, 1982.

29. Samar Ibrahim Mohamed: Jomo Kenyatta 1891-1978, African Horizons, No. 11, Volume III, 2002.

30. Mohamed Essa El-Sharkawy: The Political Map in Kenya after Kenyatta, Journal of International Politics, Egypt, No. 55, 1979.

31. Al-Ahram: 32644, Kissinger, Kenya, April 26, 1976.

32. Daily Telegraph: U.S. Defense Secretary for Kenya and Zaire, our Washington Staff, p.4, 14, June. 1976.

33. Flora Lewis: Rumsfeld to Discuss Military Aid with Kenya, Zaire on African Trip, International Herald Tribune, p.1, 15, June. 2019.

34. The Times: America to supply planes worth $£ 44 m$ to Kenya, p.8, 17, June. 1976.

35. International Herald Tribune: Kenya Receives Shipment of U.S. Warplanes, 12, Apr, 1978.

36. https://www.britannica.com/biography/Tom-Mboya

37. https://www.britannica.com/biography/Oginga-Odinga 